RESEARCH PAPER RP1448

\author{
Part of Journal of Research of the National Bureau of Standards, Volume 28 \\ January 1942
}

\title{
APPLICATION OF THE DROPPING-MERCURY ELECTRODE TO THE INVESTIGATION OF THE POLYHYDROXY ACIDS AND LACTONES
}

\author{
By Harry Matheson, Horace S. Isbell \\ and Edgar Reynolds Smith
}

\section{ABSTRACT}

The polarographic method is used in a study of the polyhydroxymonocarboxylic acids, their lactones, lactides, and other condensation products. With a tetraethylammonium chloride environment, polarographic waves are obtained which show the behavior of the hydroxy acids and their lactones with respect to electrolytic reduction and the products which they form in dilute aqueous solution.

Freshly prepared solutions of the aldonic acids give the ordinary hydrogen wave but do not give waves which correspond to the reduction of the carboxyl group. When a solution containing an aldonic acid is allowed to stand, the wave due to the hydrogen ion decreases and a wave caused by the gamma lactone appears. In the presence of oxygen a wave, apparently caused by some substance produced by the interaction of the sugar acid, mercury, and oxygen, forms at about $-1.1 \mathrm{v}$. The formation of this wave is accompanied by a corresponding decrease in the hydrogen wave. Freshly prepared solutions of the delta lactones of the aldonic acids give waves at about $-2.3 \mathrm{v}$, with respect to a mercury anode, which appear to be due to the reduction of the lactones. The heights of these waves decrease with time until, after several hours, they disappear. The absence of an appreciable delta lactone wave in a $0.01 M$ aqueous solution of an aldonic acid shows that the position of the equilibrium between the free acid and the delta lactone is far toward the free acid. The gamma lactones of the aldonic acids give polarographic waves at potentials slightly higher than the delta lactones. When a solution containing a gamma lactone is allowed to stand, the height of the gamma lactone wave decreases while a wave corresponding to the reduction of the hydrogen ion appears. The inflection points for the gamma lactone waves vary only slightly with the configuration of the groups comprising the lactone structure. This small variation in the inflection points shows a regularity which indicates that the stereomeric positions of the hydroxyl groups are of importance. When the hydroxyl of carbon 2 and the residual carbon group attached to carbon 4 are in the cis position, the reduction potential seems to be higher than it is when these groups are in the trans position.

\section{CONTENTS}

I. Introduction $\ldots \ldots \ldots$

II. Outline of experimental method and results

III. Apparatus and procedure.... 100

1. Electric circuit.

2. Electrodes.....

3. Preparation of the solutions for polarographic measurement...... 102

4. Measurement of polarograms ....... 103

IV. Application of the polarographic method to the study of the formation and splitting of lactones . . 
V. Effect of configuration and structure on the reduction potentials of the

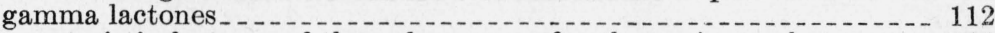

VI. Characteristic features of the polarograms for the various substances _- 114

1. Glycolic acid _...

2. Lactic acid, lactyllactic acid, and lactide

3. Glyceric acid. .

4. $d$-Erythrono- $\gamma$-lactone. . . . . . . . .

5. $l$-Threono- $\gamma$-lactone

6. $l$-Arabono- $\gamma$-lactone $\ldots \ldots \ldots \ldots \ldots \ldots$

7. $l$-Ribono- $\gamma$-lactone

8. $d$-Xylono- $\gamma$-lactone. . _ .

9. $d$-Lyxono- $\gamma$-lactone

10. $l$-Rhamnono-lactones _._.

11. $d$-Gluconic acid and its lactones_....................... 120

12. $d$-Galactonic acid and its gamma lactone

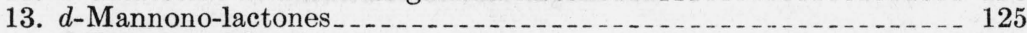

14. $d$-Talonic acid and its gamma lactone

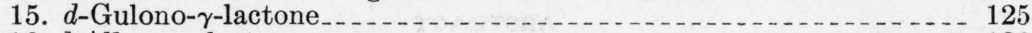

16. $l$-Allono- $\gamma$-lactone $\ldots \ldots \ldots \ldots \ldots \ldots \ldots$

17. $d-\alpha$-Galaheptono- $\gamma$-lactone_._.

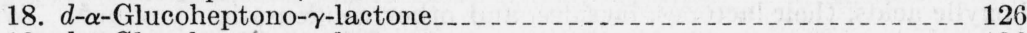

19. $d-\beta$-Glucoheptono- $\gamma$-lactone

20. $d-\alpha$-Mannoheptono- $\gamma$-lactone $\ldots \ldots \ldots \ldots$

21. $d-\beta$-Mannoheptonic acid and its gamma lactone

22. $d-\alpha$-Guloheptonic acid and its gamma lactone $\ldots$

23. $d-\beta$-Guloheptonic acid__._.

24. Lactobiono- $\delta$-lactone _._.

VII. References__ _ _ _ _ 131

\section{INTRODUCTION}

The hydroxy acids, of which lactic acid and gluconic acid are important examples, combine within themselves the properties of a carboxylic acid and of an alcohol, and consequently are capable of forming derivatives both as acids and as alcohols. All hydroxy acids lose water under certain conditions to yield esterlike compounds, of which the lactides and lactones are typical examples. When the hydroxy acid is dissolved in water, the esterification reactions may occur spontaneously to establish an equilibrium between the free acid and various condensation products. The condensation may take place between the carboxyl of one molecule and a hydroxyl of another, or it may take place intramolecularly. Thus, two molecules of glycolic acid combine with the loss of one molecule of water to give diglycolic acid (I), or with loss of two molecules of water to form glycolide (II); lactic acid forms an analog of diglycolic acid and also the lactide (III); erythronic acid forms the gamma lactone (IV); gluconic acid forms a gamma lactone (V), a delta lactone (VI), and a condensation product of unknown structure. The lactides and lactones can be isolated under suitable conditions and their presence in relatively concentrated solutions can be readily shown, but heretofore no suitable method has be en available for investigating the composition of very dilute solutions of such compounds. 
<smiles>O=C(O)COC(=O)CO</smiles>

I. Diglycolic acid<smiles>CC1OC(=O)C(C)O1</smiles>

III. Lactide<smiles>O=CCC(O)C(O)CO</smiles>

V. $d$-Glucono- $\gamma$-lactone<smiles>O=C1CCOC(=O)O1</smiles>

II. Glycolide<smiles>O=CCC(O)C(O)CO</smiles>

IV. $d$-Erythrono- $\gamma$-lactone<smiles>O=CCOCC(O)C(O)CO</smiles>

VI. $d$-Glucono- $\delta$-lactone

The polarographic method for the determination of "reduction potentials" ${ }^{1}$ by means of the dropping-mercury electrode is particularly useful for the detection of reducible substances. Prior investigations have established that the esters, lactones, and anhydrides of carboxylic acids can be reduced chemically, whereas the free acids are extremely resistant to reduction. The reduction of the lactones of the aldonic acids is a reaction of importance, as it serves as a means of passing from the acid to the corresponding aldose, which may then be reduced to the alcohol. Although in polarographic investigations the conditions differ considerably from those commonly used in chemical reductions, it seemed probable that use of the polarographic method would give "reduction potentials" and would provide a means for studying the equilibrium between the hydroxy acids and their condensation products.

\section{OUTLINE OF EXPERIMENTAL METHOD AND RESULTS}

The experimental approach to the problem, in its broader aspects, was somewhat empirical. Solutions of the pure acids, lactones, and lactides in several simple environmental solutions were prepared, and

1 These "reduction potentials" are not, in all cases, the "redox" potential of an oxidant-reductant pair. 
polarograms were made from time to time. The polarograms often showed typical reduction waves, which occurred at characteristic potentials and varied in height as the composition of the solutions changed with either the formation or the cleavage of the esterlike compounds.

To determine experimental conditions which bring out the characteristic waves for the substances under investigation, measurements were made in several environmental solutions. Müller $[1]^{2}$ has shown the desirability of using buffered environmental solutions in organic polarographic work, and in our early measurements attempts were made to use solutions buffered with lithium phosphate $(0.05 \mathrm{M}, \mathrm{pH}$ 6.4) and lithium tetraborate $(0.05 \mathrm{M}, \mathrm{pH} 9.1)$; but on account of the neutralizing action of the buffer and the reduction of the lithium ion, the solutions did not give waves characteristic of the acids or the lactones. Measurements with unbuffered solutions containing lithium chloride revealed waves which appeared to be characteristic of the gamma and delta lactones; but for many of the aldonic acids these waves occurred at potentials near the decomposition potential of lithium chloride, and consequently the measurements were not satisfactory. Thus, it was necessary to use a supporting electrolyte which has a very high decomposition potential, and tetraethylammonium chloride was selected for this purpose.

In agreement with their chemical properties. the freshly dissolved aldonic acids give a large wave at the potential corresponding to the reduction of hydrogen ion but fail to give any other waves. The freshly dissolved delta and gamma lactones do not give the hydrogen wave but give waves presumably caused by the reduction of the lactone to the corresponding sugar, at potentials which range from -2.2 to -2.7 v. With the exception of the wave for $d$-glucono- $\gamma$ lactone, which occurred at $-2.2 \mathrm{v}$, the waves for the 17 gamma lactones studied occurred at potentials ranging from -2.4 to $-2.7 \mathrm{v}$. In some cases there appear to be two waves which suggest a stepwise reduction, or the progressive reduction of the lactone (see the curve for lactobiono- $\delta$-lactone, fig. 2). The delta lactones of $d$-gluconic, $d$-mannonic, and $l$-rhamnonic acids appear to be reduced at slightly lower potentials than the corresponding gamma lactones. It is of interest to note also that the delta lactone of lactobionic acid is reduced at approximately the same potential as the delta lactone of $d$-gluconic acid. Thus, a galactosido group attached to carbon 4 of $d$-glucono- $\delta$-lactone does not materially alter the reduction potential. Compounds of the lactide type seem to give a wave at about $-2.2 \mathrm{v}$. The polarograms given in figures 1 and 2 illustrate the character of the curves obtained for free acids, lactones, and lactide. The changes in the polarograms which were found to take place when the solutions were allowed to stand are discussed in section IV, and a more detailed description of the apparatus and the procedure is given in the next section.

\footnotetext{
2 Figures in brackets indicate the literature references at the end of this paper.
} 

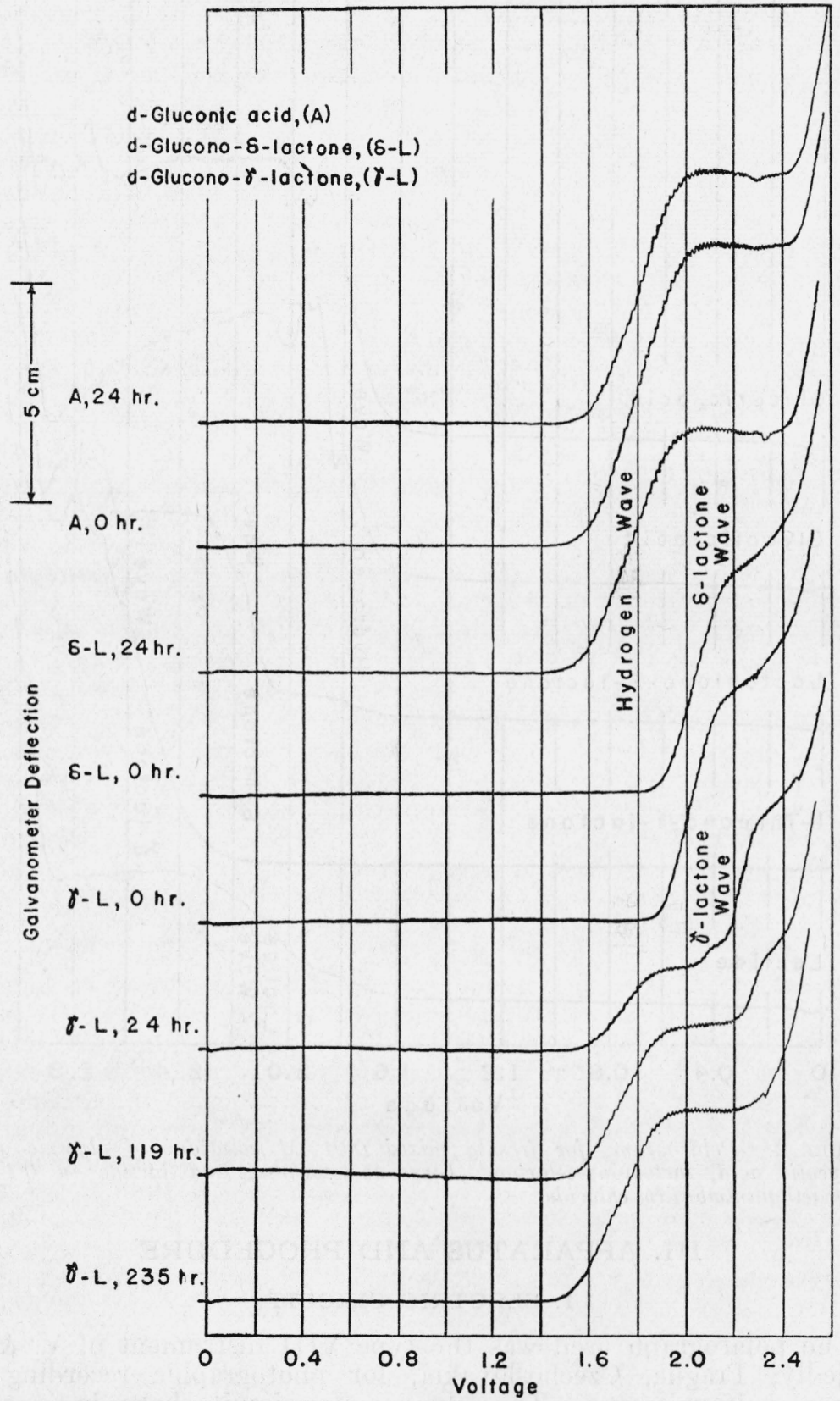

Figure 1.-Polarograms for $0.01 M$ solutions of d-gluconic acid, d-glucono- $\delta$ lactone, and d-glucono- $\gamma$-lactone in $0.05 \mathrm{M}$ lithium chloride.

These curves may be compared with those of figure 9, which are for the same compounds in $0.1 M$ tetraethylammonium chloride. 


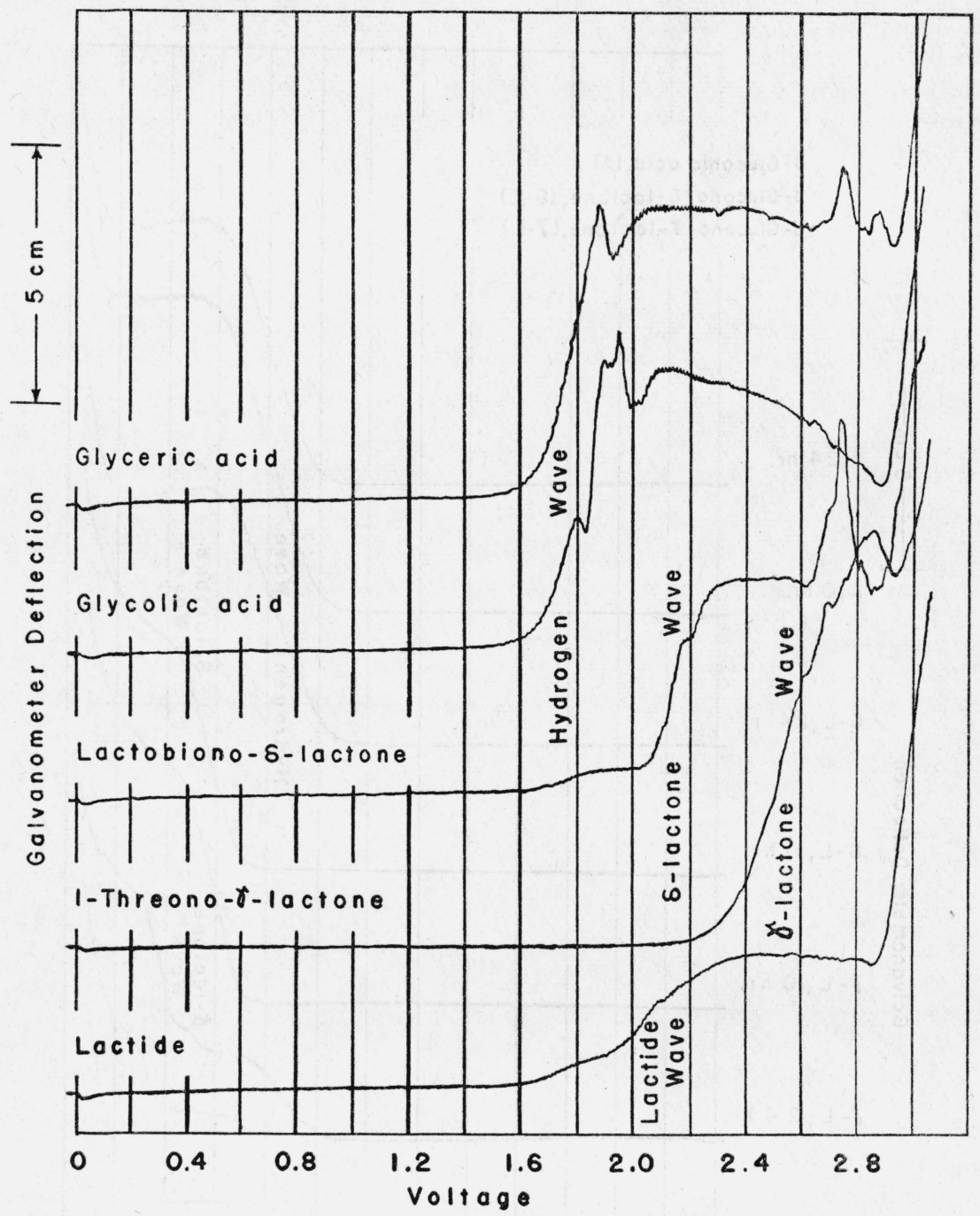

Figure 2.-Polarograms for freshly mixed $0.01 M$ solutions of glyceric acid, glycolic acid, lactobiono- $\delta$-lactone, l-threono- $\gamma$-lactone, and lactide in $0.1 M$ tetraethylammonium chloride.

\section{APPARATUS AND PROCEDURE}

\section{ELECTRIC CIRCUIT}

The polarograph used was the type VIII instrument of V. \& J. Nejedlý, Prague, Czechoslovakia, for photographic recording of current-voltage curves. The galvanometer circuit, shown in figure 3, includes an Ayrton-Mather universal shunt, labeled sensitivity control, which was supplied with the instrument. The circuit was improved by two modifications, labeled compensating resistor and constantdeflection circuit. 
The compensating resistor is a five-dial decade resistance box, inserted between the polarograph and the universal shunt, which may be adjusted so that the resistance of the galvanometer circuit, viewed from the polarograph, is substantially independent of the setting of the shunt. With this arrangement, the galvanometer sensitivity may be varied without causing any appreciable variation in the external resistance. In some instances this is of importance, since the appearance of certain types of maxima on the currentvoltage curve may be altered by changes in external resistance [2, 3]. Throughout this investigation the compensating resistor was adjusted so that the resistance of the galvanometer circuit between the terminals which connect the galvanometer to the polarograph was $1,498 \mathrm{ohms}$.

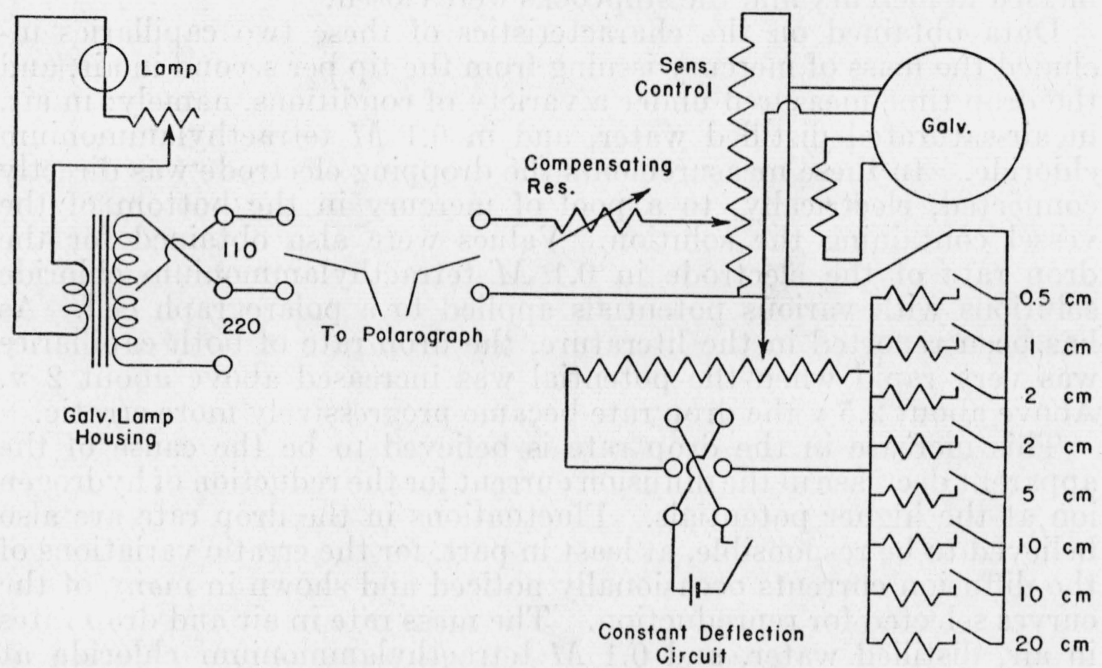

FIGURE 3.-Auxiliary circuits for polarograph.

The constant-deflection circuit consists of a 1.5-v flashlight cell and a high-resistance network designed to provide a convenient means of altering the apparent rest point of the galvanometer when several curves are recorded on a single sheet of photographic paper. The resistances within this network were of the order of megohms, so that their presence had no detectable effect on the deflections of the galvanometer produced by currents from the polarograph.

The current sensitivity of the galvanometer, including the universal shunt and compensating resistance in the circuit, was measured ${ }^{3}$ for the constant-circuit resistance of $1,498 \mathrm{ohms}$, at different settings of the universal shunt, with a scale at the same distance from the galvanometer $(1 \mathrm{~m})$ as the recording paper was during the polarographic measurements. The current sensitivity used throughout this investigation was $6.44 \times 10^{-7} \mathrm{amp} / \mathrm{mm} / \mathrm{m}$, which was obtained with the universal shunt set at $1 / 300$.

\section{ELECTRODES}

A constant-level, dropping-mercury electrode of the type described by Mueller [4] was used for the measurements of the $d$-gluconolac-

${ }^{3}$ These measurements were kindly made by D. Ramaley of the Electricity Division of this Bureau. 
tones, shown in figures 4 and 5 , for the investigation of lactic acid and $d$-lyxono- $\gamma$-lactone, and for obtaining a few duplicate curves for $d-\alpha$ glucoheptono- $\gamma$-lactone and $d$ - $\beta$-glucoheptono- $\gamma$-lactone. For all other measurements the electrode consisted of a Jena glass capillary, supplied with the instrument, sealed to an ordinary 250 -ml soft-glass separatory funnel. With an electrode of this type the beight of the mercury surface above the tip is not constant, so that the drop rate is not strictly uniform. However, as the amount of mercury issuing from the capillary per minute is very small, the drop rate changes very slowly. Mercury was added to the reservoir from time to time so that the greatest variation in the mercury head was $5 \mathrm{~mm}$ in $24 \mathrm{~cm}$.

When the electrodes were not in use, the capillary tips were immersed in mercury and the stopcocks were closed.

Data obtained on the characteristics of these two capillaries included the mass of mercury issuing from the tip per second in air, and the drop time measured under a variety of conditions, namely: in air, in air-saturated distilled water, and in $0.1 M$ tetraethylammonium chloride. In these measurements the dropping electrode was directly connected, electrically, to a pool of mercury in the bottom of the vessel containing the solution. Values were also obtained for the drop rate of the electrode in $0.1 M$ tetraethylammonium chloride solutions with various potentials applied to a polarograph cell. As has been reported in the literature, the drop rate of both capillaries was very rapid when the potential was increased above about $2 \mathrm{v}$. Above about $2.5 \mathrm{v}$ the drop rate became progressively more erratic.

This increase in the drop rate is believed to be the cause of the apparent decrease in the diffusion current for the reduction of hydrogen ion at the higher potentials. Fluctuations in the drop rate are also believed to be responsible, at least in part, for the erratic variations of the diffusion currents occasionally noticed and shown in many of the curves selected for reproduction. The mass rate in air and drop rates in air, distilled water, and $0.1 M$ tetraethylammonium chloride at zero applied voltage for the Mueller capillary were $4.46 \mathrm{mg} / \mathrm{sec}, 33.6$ $\mathrm{sec} /$ drop, $6.8 \mathrm{sec} /$ drop, and $6.0 \mathrm{sec} /$ drop, respectively; and for the Jena capillary at the lowest pressure were $2.42 \mathrm{mg} / \mathrm{sec}, 18.7 \mathrm{sec} /$ drop, 3.0 sec/drop, and $2.8 \mathrm{sec} /$ drop; and at the greatest hydrostatic head were $2.52 \mathrm{mg} / \mathrm{sec}, 17.7 \mathrm{sec} /$ drop, $2.9 \mathrm{sec} /$ drop, and $2.7 \mathrm{sec} /$ drop, respectively.

The anode potential in solutions which contain chloride ion is, in general, fairly stable. The anode potential relative to a normal calomel electrode with liquid junction was measured in two environments before, during, and after the taking of a polarogram. In the $0.1 M$ lithium chloride solution the anode potential is $+0.061 \pm 0.001$ $\mathrm{v}$; in the $0.1 M$ tetraethylammonium chloride solution it is +0.055 $\pm 0.005 \mathrm{v}$. In both cases the anode is positive with respect to the normal calomel electrode. The potentials reported in this paper are with respect to the mercury anode but may be referred to the normal calomel electrode, if desired, by means of these values.

\section{PREPARATION OF THE SOLUTIONS FOR POLAROGRAPHIC MEASUREMENT}

Since many of the compounds studied in this investigation are subject to hydrolysis and other changes when in solution, a technique 
was developed by which the first polarogram was started within 2 to 5 minutes after the first wetting of the solid compound. The vessels used to contain the solutions were of the Erlenmeyer type in which a pool of pure mercury served as the anode. The purified salt ${ }^{4}$ to be used as the environmental electrolyte was dissolved in distilled water in a fritted quartz crucible and filtered, with suction, into a quartz vessel. The chloride in a weighed amount of the stock solution was determined gravimetrically as silver chloride. From this stock solution a 0.1 molal solution was made up in quartz ${ }^{5}$ as needed.

Ordinarily, $9 \mathrm{ml}$ of the 0.1 molal solution containing the desired environmental salt was placed in the cell, and oxygen was eliminated by bubbling through the solution commercial nitrogen, freed from oxygen by passage through an electrically heated furnace charged with copper. After about 30 minutes, when oxygen had been removed from the cell, $1 \mathrm{ml}$ of a freshly prepared solution, containing the desired quantity of the compound in oxygen-free water, was added and the polarogram started. The times of wetting the sample, introducing the solution into the cell, and starting the polarogram were noted. After the polarogram was completed, the cell was stoppered and the solution was allowed to stand at room temperature. Whenever solutions were investigated more than 1 day after mixing, they were protected from molds by the addition of several drops of xylene. Control experiments showed that the addition of xylene had no effect on the polarograms.

\section{MEASUREMENT OF POLAROGRAMS}

The potentials of the inflection points of the waves were measured, and are given with respect to the mercury anode. In the absence of a maximum, the inflection point of a symmetrical wave with a steep slope may be located with precision; but if the slope is not steep, the exact location of the inflection point becomes doubtful. In the presence of a maximum or when a wave is not symmetrical about its inflection point, as is the case when two waves are partially merged, the estimate may be uncertain by $0.05 \mathrm{v}$ or more. Because of the uncertainty in the measurement and the variation of the potential with the experimental conditions, no attempt has been made to correct for the IR drop in the solutions. In the tetraethylammonium chloride environment, the polarograms for the acids show a pronounced pointed maximum, associated with the hydrogen wave, which is completed at potentials considerably less than those necessary to develop the diffusion current. Such a maximum is shown, for example, in figure 2. In many cases, though the wave height decreases when the solution is allowed to stand, the height of the maximum decreases more rapidly, so as to give the appearance of two waves with inflection points at nearly the same potential. On further decrease of wave height there ceases to be any evidence that two waves are involved (see fig. 10). With several solutions prepared from lactones, the hydrogen wave develops on standing and the reverse phenomena are observed, that is, a single small wave as it grows takes on the appearance of two waves, one of which, on continued growth, shows a small pointed maximum (see figs. 5 and 8 ).

4 A method for the purification of tetraethylammonium chloride will be published later.

$\checkmark$ In Pyrex cells at a sensitivity of 110 , a slight alkali metal wave which increased definitely with time could be detected in 0.1 molal solution. 
Since the reductions leading to the polarographic activity of the compounds of the present investigation are probably not reversible, the apparent potentials of the inflection points may be expected to change with changes in concentration and environment, by amounts several times as large as could be explained on the basis of experimental error. In the tetraethylammonium chloride environment used in our later work, the hydrogen and lactone waves occur at more negative potentials than in the lithium chloride environment used in our earlier work.

Müller [1] has discussed the effect of acidity and buffers on the appearance and position of waves due to both reversible and irreversible reactions in which hydrogen ion is involved. In connection with our work, it is sufficient to point out that when a reaction occurs at the dropping electrode the $\mathrm{pH}$ in the vicinity of the electrode may be quite different from that in the bulk of the solution. It will, in general, depend not only on the reaction occurring but also on its rate at any instant; and, as a result, the position and form of the resulting polarographic wave will be affected by the acidity of the main body of the solution, the buffering capacity of the environment, the characteristics of the capillary, and the concentration of the reacting substance.

The wave heights were estimated with the aid of a pair of dividers as the net vertical displacement. In many cases the waves were well defined and the heights could be determined within 5 percent. In other cases, especially with the waves in an environment of $0.1 M$ tetraethylammonium chloride at potentials more negative than -2.5 $\mathrm{v}$, the diffusion currents were erratic and often the appearance of the whole wave was distorted by this behavior. Naturally, the estimation of the height of such a wave is very uncertain and the error may amount to as much as 25 percent. In discussing the results we have ignored the implications of the Ilkovič equation, which correlates the diffusion current with the product of the concentration and the number of electrons involved per molecule, because the reductions appear to be irreversible and the drop-rate of the capillary changes rapidly with potential in the region where most of the waves occur.

\section{APPLICATION OF THE POLAROGRAPHIC METHOD TO THE STUDY OF THE FORMATION AND SPLITTING OF LACTONES}

In previous publications [5] it has been shown that sugars which have like configurations for the first five carbon atoms exhibit similar mutarotation reactions and establish similar equilibrium states involving the pyranose, furanose, and open-chain modifications. ${ }^{6}$ Likewise aldonic acids which have similar configurations resemble one another in that they establish equilibrium states which involve similar proportions of their gamma and delta lactones. The formation and splitting of aldonic lactones have been investigated in concentrated solutions [7], but very little is known about these reactions in dilute aqueous solution. In fairly concentrated solutions, delta lactones are formed and split much more rapidly than the corresponding gamma lactones. For example, when $d$-gluconic acid is

\footnotetext{
B Recently Cantor and Peniston [6] have shown that the polarographic method may be used to estimate the amounts of the open-chain modification present in sugar solutions.
} 
dissolved in water, the delta and gamma lactones are formed simultaneously; but, since the delta lactone is formed more rapidly than the gamma, its concentration reaches a maximum in 4 or 5 hours and then decreases as more of the sugar acid is converted to the gamma lactone. When $d$-glucono- $\delta$-lactone is dissolved in water, it is hydrolyzed rapidly, and in the course of several hours an equilibrium is established with the free acid, while the gamma lactone is formed slowly at the expense of both the free acid and the delta lactone. When $d$-glucono- $\gamma$-lactone is dissolved in water, it is hydrolyzed slowly, and in the course of many days an equilibrium is established with the acid and delta lactone. All aldonic acids form this type of equilibrium, whose position depends on the experimental conditions and on the structure and configuration of the aldonic acid. Concentrated equilibrated solutions of aldonic acids which have the manñonic, gulonic, allonic, or talonic configuration usually contain large quantities of the gamma lactones, which can be crystallized readily. Concentrated solutions of $d$-gluconic acid contain substantial quantities of both the delta lactone and the free acid and yield either $d$ glucono- $\delta$-lactone or $d$-gluconic acid, according to whether crystallization is conducted at high or low temperatures. Thus, it is apparent that concentrated solutions of the aldonic acids in equilibrium contain delta and gamma lactones in substantial quantities. Since the lactones react with water, the proportion of lactone in the acidlactone mixture depends on the concentration and on the equilibrium constants of the acid-lactone interconversion reactions. Thus, information concerning the composition of the equilibrium mixture in dilute aqueous solutions of the aldonic acids is of both theoretical and practical value. Although the quantitative results obtained by application of the polarographic method to the problem appear to be somewhat limited, nevertheless they reveal considerable information.

Figures 4 and 5 show the changes in the polarograms of $0.01 M d$ glucono- $\delta$-lactone and $0.01 M d$-glucono- $\gamma$-lactone in $0.1 M$ tetraethylammonium chloride solutions on standing. From the heights of the waves at various times, curves may be constructed to show changes in the compositions of the solutions. ${ }^{7}$ A number of these curves are shown in figures 6 and 7 .

The freshly prepared solution of $d$-glucono- $\delta$-lactone did not give a hydrogen wave, but after the solution had stood for only a few minutes a hydrogen wave appeared and increased in height while the delta lactone wave decreased until, after 3.3 hours, it was not visible. Inasmuch as the delta lactone waves for $d$-glucono-, $d$-mannono-, $l$ rhamnono-, and lactobiono- $\delta$-lactone disappear completely in the course of several hours, the equilibrium states for $0.01 M$ solutions of the corresponding acids do not appear to contain appreciable quantities of the delta lactones. The absence of the delta lactone wave in $0.01 M$ solution at equilibrium is surprising, since $d$-glucono- $\delta$-lactone crystallizes readily from concentrated aqueous solutions of $d$-gluconic acid. The polarograms for dilute solutions prepared from other aldonic acids, after standing for sufficient time to permit establishment of equilibrium between the acid and the delta lactone, fail to show definite waves corresponding to the delta lactones. With a few of the

7 Velocity constants for the lactone formation and cleavage reactions may be calculated from the wave heights, but these are not included because it seemed desirable to make measurements at different acidities and under more closely controlled conditions before calculating velocity constants. 


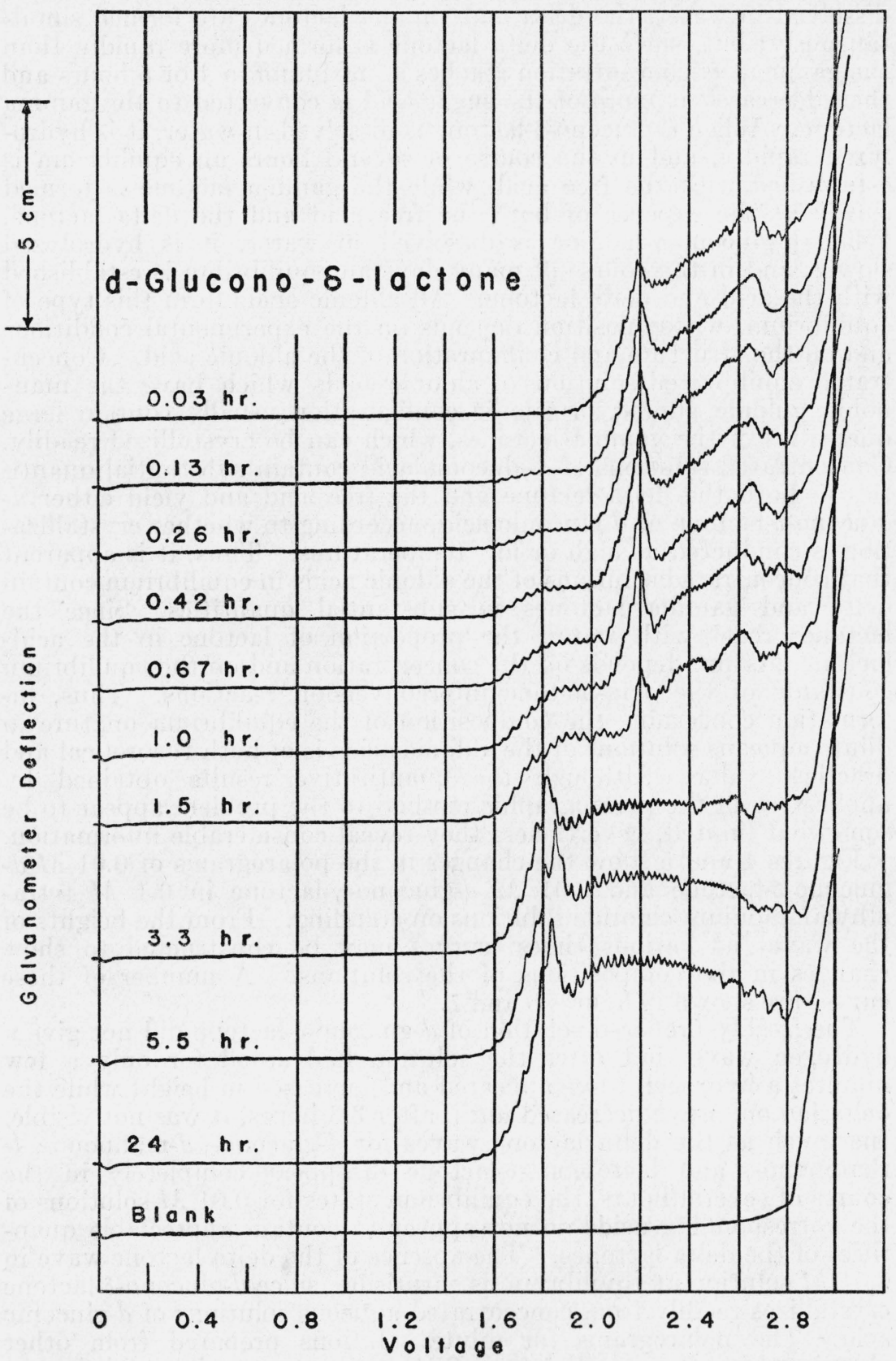

FigURE 4.- $d$-Glucono- $\delta$-lactone, $0.01 M$, in $0.1 M$ tetraethylammonium chloride.

The times given are measured from the first wetting of the solid to the starting of the polarogram. The polarograph was set to increase the potential $0.536 \mathrm{v} / \mathrm{min}$.

The curves were made using a freshly recrystallized sample and the constant-level capillary. As a result they are comparable only qualitatively with those for the same compound shown in figure 9 . 


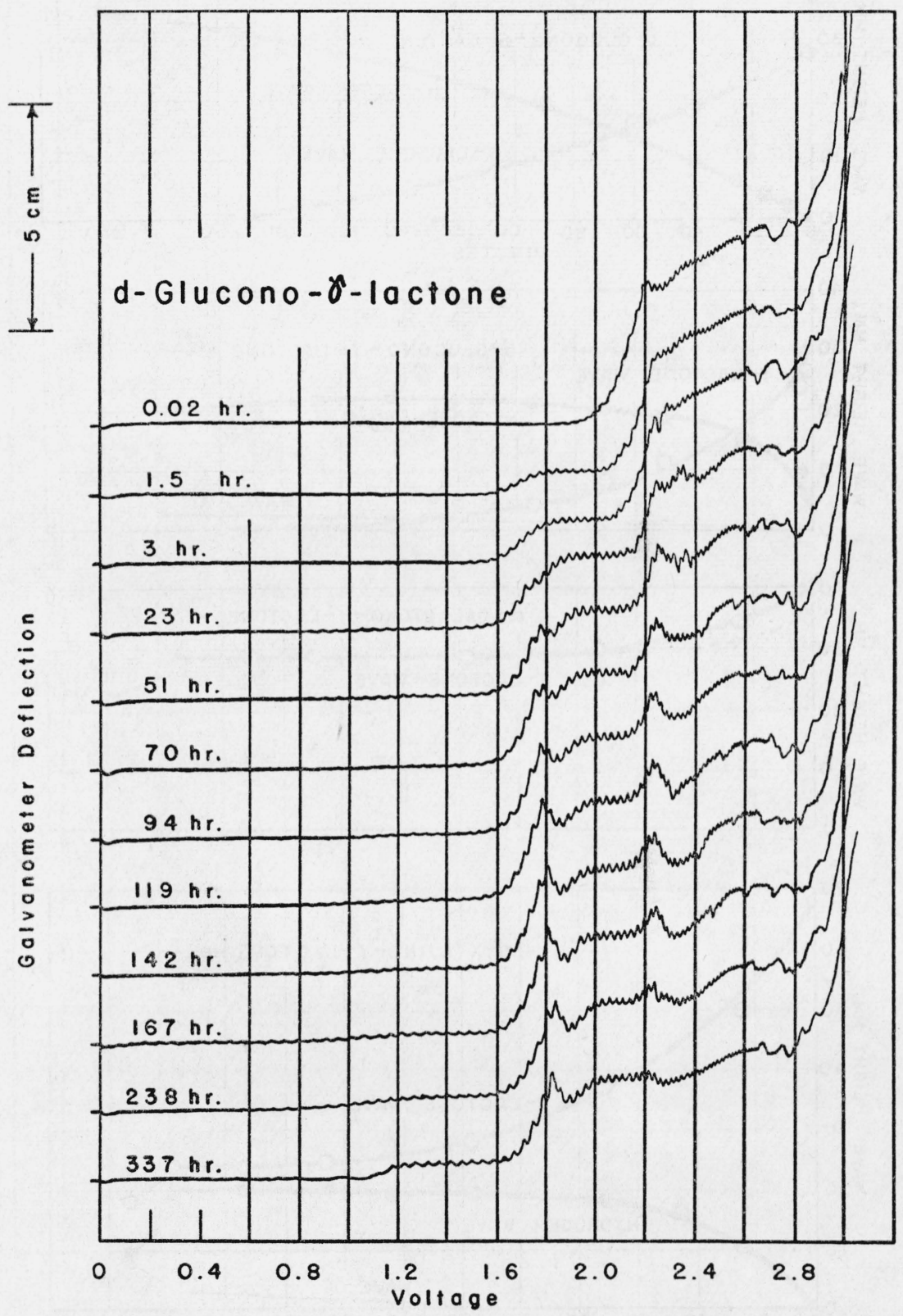

FigURE 5.- $d$-Glucono- $\gamma$-lactone, $0.01 M$, in $0.1 \mathrm{M}$ tetraethylammonium chloride. The curves were made using a freshly recrystallized sample and the constant-level capillary. As a result they are comparable only qualitatively with those for the same compound in figure 9. 

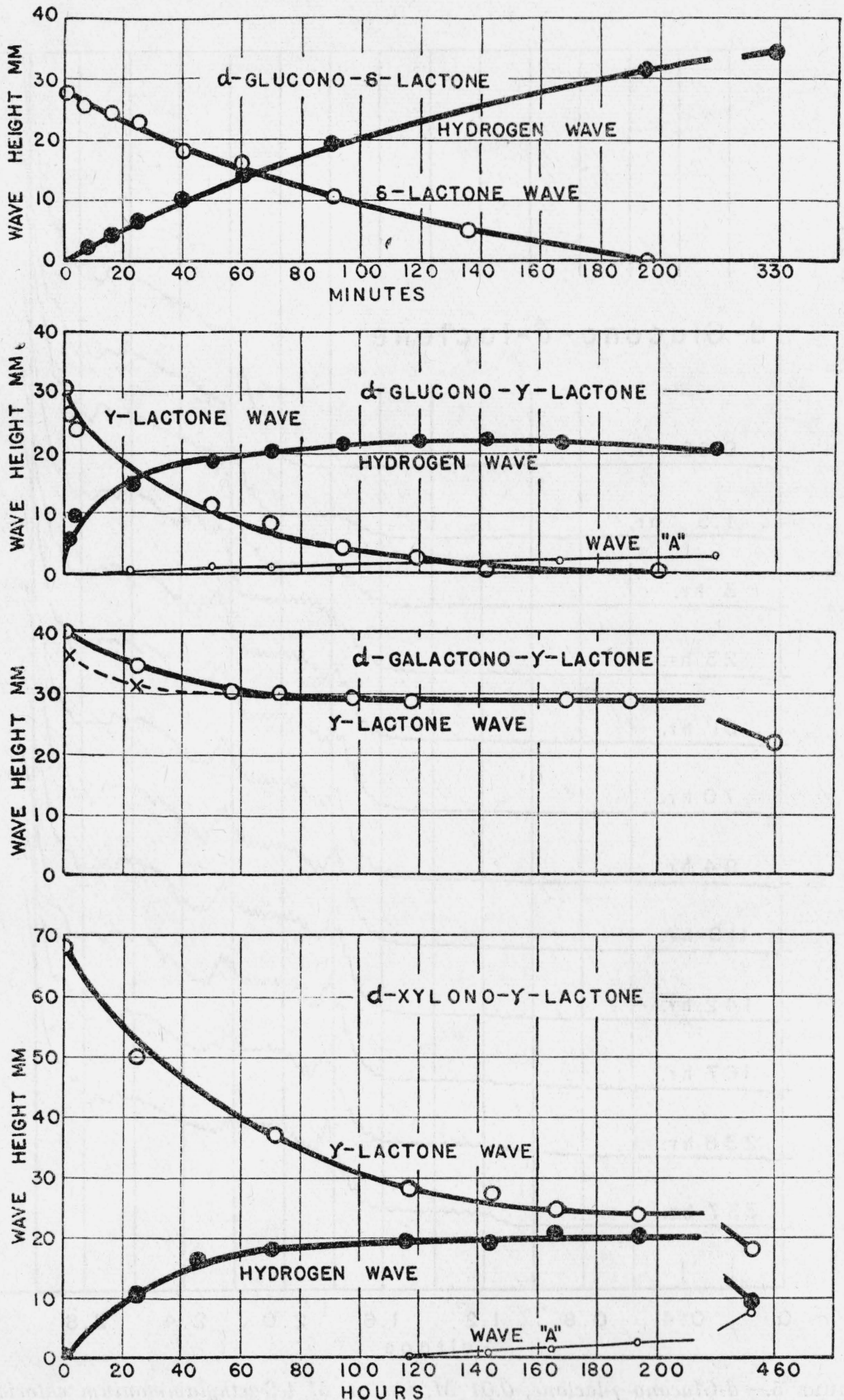

FIGURE 6.-Curves which show the change of wave height with time, at room temperature, for $0.01 \mathrm{M}$ solutions of $d$-glucono- $\delta$-lactone, $d$-glucono- $\gamma$-lactone, $d$ galactono- $\gamma$-lactone, and $d$-xylono- $\gamma$-lactone in $0.1 \mathrm{M}$ tetraethylammonium chloride. 

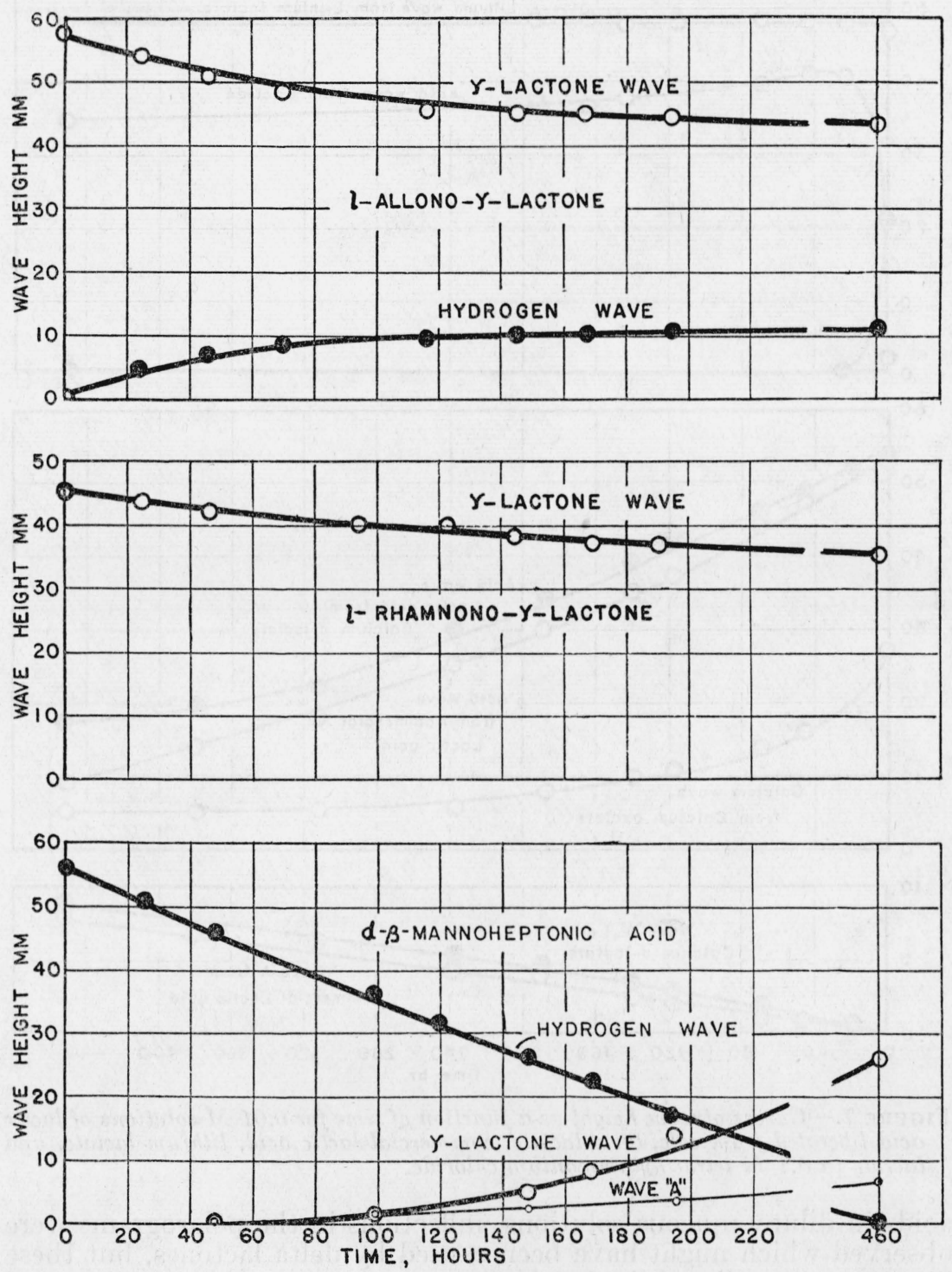

FIGURE 6 (continued).-Curves which show the change of wave height with time, at room temperature, for $0.01 \mathrm{M}$ solutions of l-allono- $\gamma$-lactone, l-rhamnono- $\gamma$ lactone, and d- $\beta$-mannoheptonic acid in $0.1 \mathrm{M}$ tetraethylammonium chloride. 

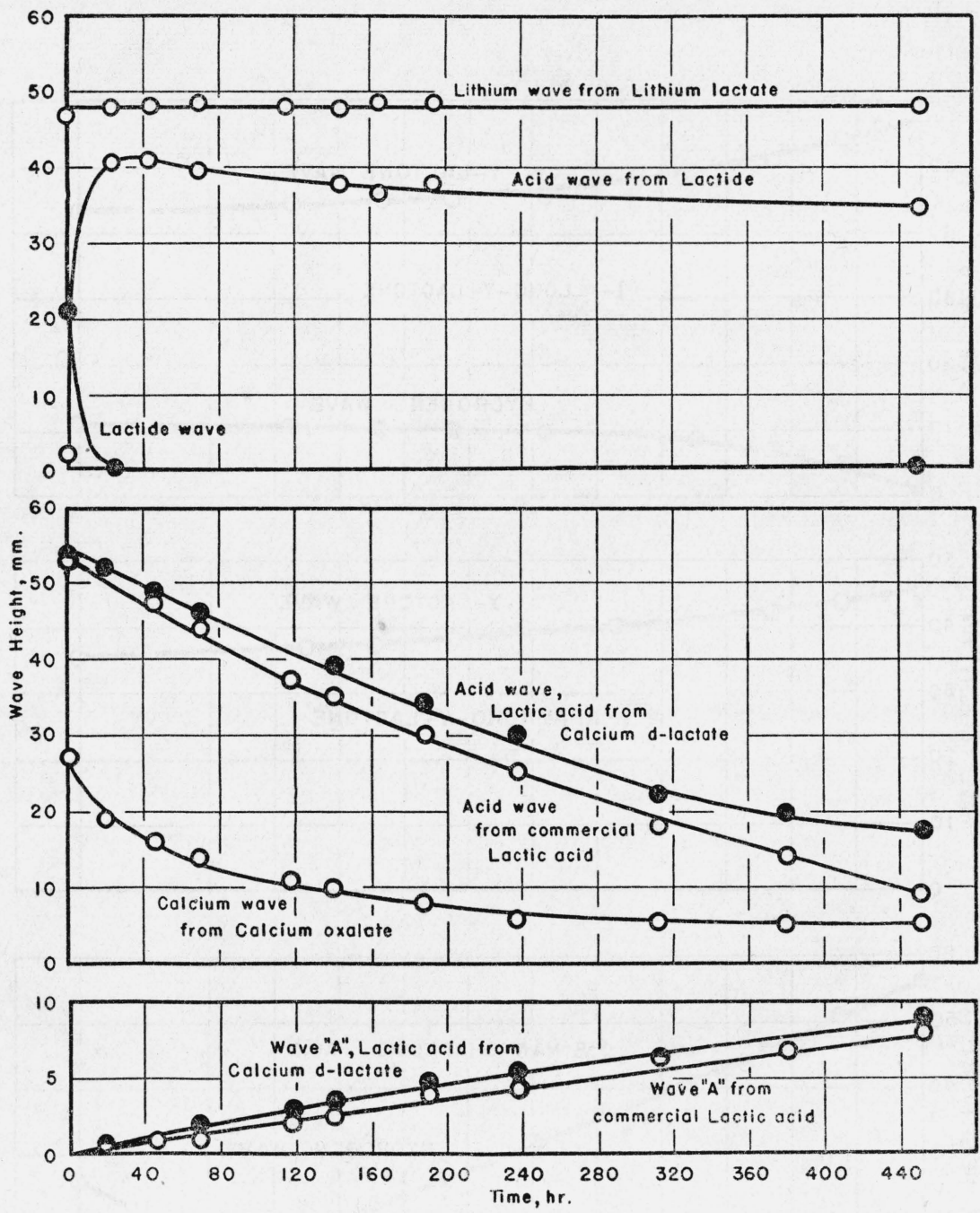

FIgURe 7.-Curves of wave height as a function of time for $0.01 M$ solutions of lactic acid liberated from calcium d-lactate, commercial lactic acid, lithium lactate, and lactide in $0.1 \mathrm{M}$ tetraethylammonium chloride.

acids in dilute aqueous solutions, inflections in the polarograms were observed which might have been caused by delta lactones, but these waves were small and doubtful.

The absence of an appreciable quantity of the delta lactone in the equilibrium mixture is in marked contrast to the presence of the gamma lactone. Every gamma hydroxy acid studied, after standing in dilute aqueous solution, developed a polarographic wave in the region characteristic of the gamma lactone. The heights of these waves increased on standing and in some cases approached the heights of the waves obtained from solutions prepared from the corresponding gamma lactones which had stood for the same length 
of time. (See the curves for $d$ - $\alpha$-guloheptonic acid and its gamma lactone, fig. 12.)

The polarograms obtained for the solutions prepared from the free acids gave, in every case, a large hydrogen wave in the range from -1.68 to $-1.88 \mathrm{v}$. When the solution containing a sugar acid was allowed to stand in the reaction vessel, the height of the hydrogen wave gradually decreased and a new wave appeared between -1.1 and $-1.2 \mathrm{v}$. In the early stages of the investigation the decrease in the height of the hydrogen wave was considered as an indication of the formation of lactones or other esterlike compounds. Measurements made with solutions which had stood in the presence and in the absence of oxygen and mercury indicate that the decrease in the height of the hydrogen wave is caused in part by dissolved oxygen in the presence of the mercury and the formation of some substance which gives the $-1.2-v$ wave. For convenience, in future discussion this wave will be designated wave $A{ }^{8}$ Unfortunately, the reaction of the sugar acids with the mercury in the cell disturbs the acid-lactone equilibrium and thus complicates the interpretations of the curves. This factor was not recognized until after most of the measurements had been completed, and consequently the experimental method was not changed to eliminate it.

The polarographic behavior of the gamma lactones in dilute aqueous solution is illustrated by the curves for $d$-glucono- $\gamma$-lactone, $d$-galactono- $\gamma$-lactone, $d$-xylono- $\gamma$-lactone, $l$-allono- $\gamma$-lactone, and $l$-rhamnono$\gamma$-lactone, (fig. 6). The relatively more rapid changes in the heights of the waves for $d$-glucono- and $d$-xylono- $\gamma$-lactone are in contrast to the slower change in the height of the wave for $l$-rhamnono- $\gamma$-lactone. Most of the gamma lactones studied are hydrolyzed at rates which lie between these extremes and give curves such as those shown for $l$-allono- and $d$-galactono- $\gamma$-lactone.

The curve for $d$-galactono- $\gamma$-lactone illustrates another interesting aspect of the work. It will be observed that the slope of the curve which represents the height of the lactone wave is somewhat greater during the first 48 hours than during the period which follows. Close examination of the polarograms taken at 0 and 24 hours (fig. 10) reveals the presence of a partially merged $-2.3-\nabla$ wave, which disappeared in 48 hours. The rate of disappearance for the wave is less than the rate of change for the delta lactones investigated, but nevertheless this wave may have been caused by the unknown delta lactone. It is of further interest that the freshly prepared solution of $d$ - $\alpha$-mannoheptono- $\gamma$-lactone gave a similar $-2.3-v$ wave which disappeared slowly, and that solutions of $d$ - $\alpha$-glucoheptono- $\gamma$-lactone, of $d$ - $\alpha$-guloheptonic acid, and of $d$ - $\beta$-guloheptonic acid gave, on standing, small waves at potentials near $-2.3 \mathrm{v}$ (figs. 11 and 12). For convenience these waves are designated as "- $-2.3-\mathrm{v}$ " waves. It is well known that the sugar acids in aqueous solution frequently give complex amorphous products of unknown structure, and it is entirely possible that these products are associated with the polarographic waves which have been noted; but further investigation is

\footnotetext{
${ }^{8}$ Although wave $A$ appears whenever acid, mercury, and oxygen are in contact, the reaction does not seem to be as simple as is indicated by the eq [8]

since in the absence of mercury a $0.001 M$ gluconic acid solution in $0.1 M$ lithium chloride seems to react with oxygen to produce a substance giving a small wave at $-1.25 \mathrm{v}$ and a marked increase in the height of the hydrogen wave. This phase of the subject warrants further study.
} 
necessary to provide a satisfactory explanation for these $-2.3-\mathrm{v}$ waves.

Table 1 gives the heights of the polarographic waves correlated with the free acids, the gamma, and delta lactones.

TABLE 1.-Heights of some of the identified polarographic waves observed with $0.01 M$ solutions in $0.1 M$ tetraethylammonium chloride (in millimeters at sensitivity $1 / 300$ )

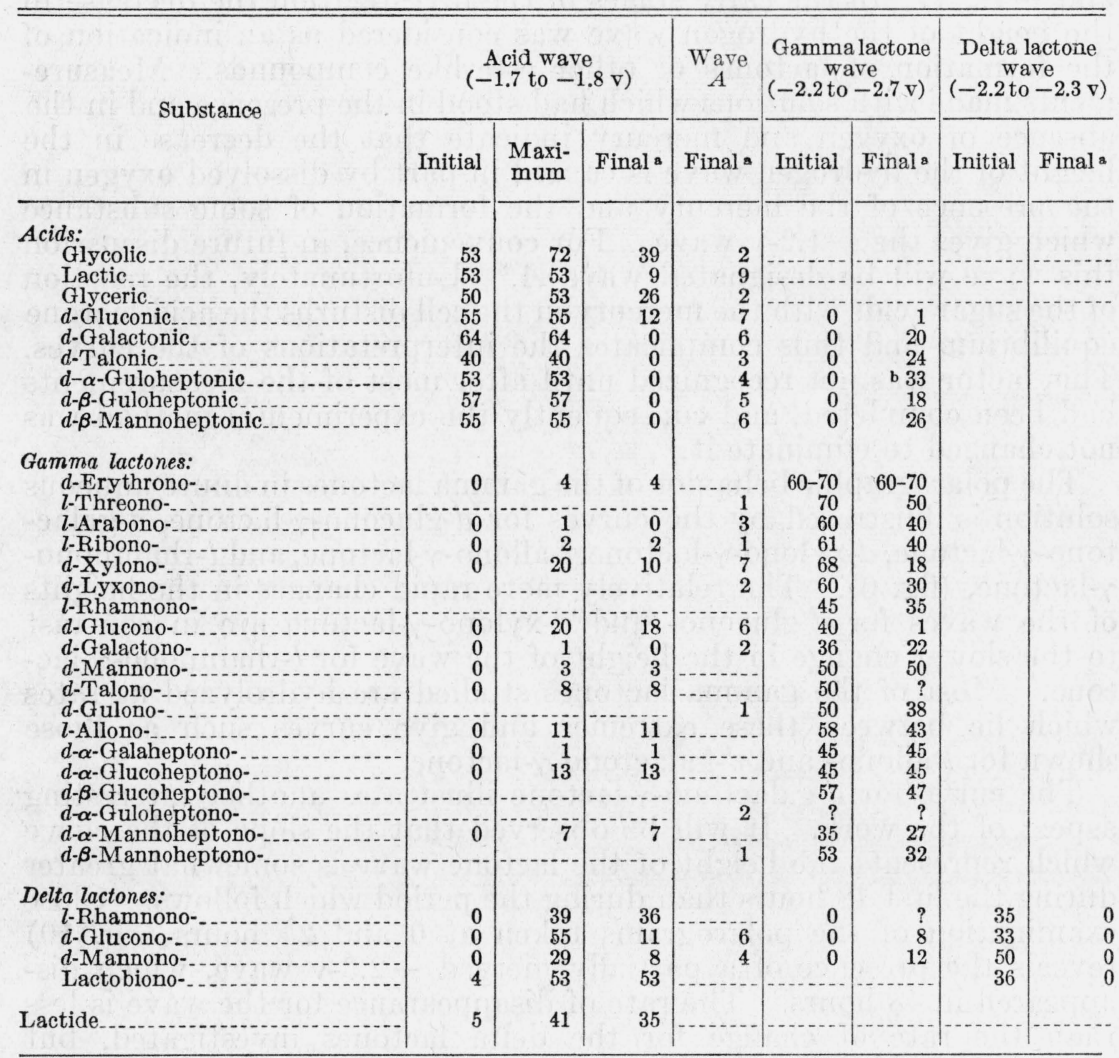

a Values obtained after approximately 450 hours at room temperature.

b Total height of what appears to be two waves, at -2.3 and $-2.6 \mathrm{v}$.

\section{EFFECT OF CONFIGURATION AND STRUCTURE ON THE REDUCTION POTENTIALS OF THE GAMMA LAC- TONES}

One of the objects of the present investigation was to ascertain whether a relation could be found between the configurations of the lactones and their reduction potentials. The different configurations for carbons 2, 3, and 4 of the gamma lactones give rise to eight isomers consisting of four pairs of enantiomorphs. Inasmuch as the enantiomorphs have like chemical properties and may be expected to have identical polarographic activity, the gamma lactones may be classified in four groups corresponding in configuration to the lactones of xylonic, ribonic, arabonic, and lyxonic acids. Since carbon 4 in $l$-threono- $\gamma-$ 
lactone and in $d$-erythrono- $\gamma$-lactone does not carry a side chain, these lactones may be classified with equal propriety in the xylonic and the lyxonic groups, respectively, or in the arabonic and the ribonic groups. In table 2 they have been placed in the former groups.

TABLE 2.-Inflection points for gamma lactones :

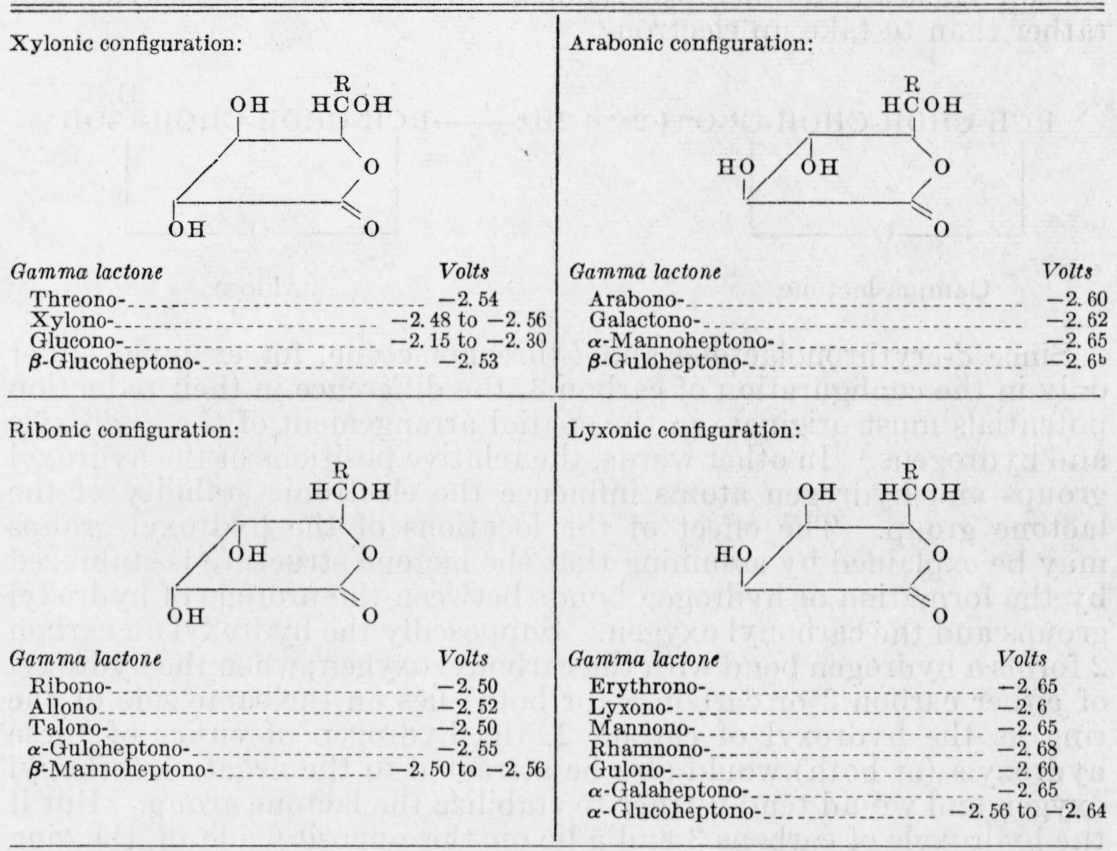

a Polarographic waves obtained with $0.01 M$ solutions of gamma lactones in $0.1 M$ tetraethylammonium chloride.

$b$ This value was obtained by measurement of a lactone solution prepared from the corresponding acid.

In table 2 the gamma lactones are listed in four groups according to configuration. The potential of the inflection point of the polarographic wave given by each lactone may be considered as a measure of the ease of reduction of that compound. With the possible exception of the values for $d$ - $\alpha$-glucoheptono- $\gamma$-lactone and $d$-glucono- $\gamma$ lactone, the potentials obtained for substances of like configuration show surprisingly small differences. In fact, the differences in the potentials for substances of like configuration in the tetronic, pentonic, hexonic, and heptonic series are for the most part within the experimental error of the measurements. When a solution of $d$ - $\alpha$-glucoheptono- $\gamma$-lactone is allowed to stand, the potential shifts to $-2.64 \mathrm{v}$, in agreement with the potentials obtained for other members of the lyxonic group. The reason for the low potential found for $d$-glucono$\gamma$-lactone is not known.

An examination of the reduction potentials in relation to the cistrans arrangements of the groups attached to the lactone ring reveals that lactones in which the $\mathrm{OH}$ of carbon 2 and the terminal $\mathrm{CH}_{2} \mathrm{OH}$ group lie on the same side of the ring (cis) give reduction potentials in the range from -2.6 to $-2.7 \mathrm{v}$, whereas lactones in which these groups 
lie on opposite sides of the ring (trans) give reduction potentials in the range from -2.2 to $-2.55 \mathrm{v}$ when the substances are in the tetraethylammonium chloride environment.

Supposedly the reduction of a lactone, represented by the equation given below, involves the addition of two electrons to carbon 1 followed by the acquisition of two protons, and the reduction potential can be considered as a function of the tendency of the lactone to exist as such, rather than to take up electrons.

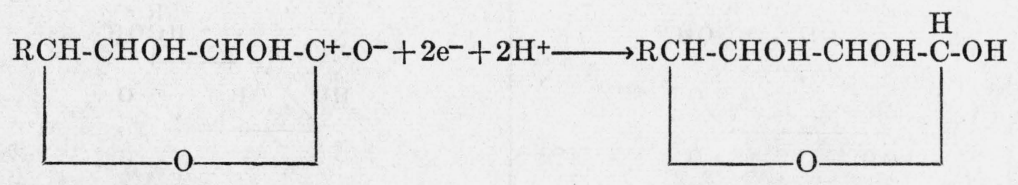

Gamma lactone

Aldose

Since $d$-erythronolactone and $l$-threonolactone, for example, differ only in the configuration of carbon 3 , the difference in their reduction potentials must originate in the spatial arrangement of the hydroxyls and hydrogens. In other words, the relative positions of the hydroxyl groups and hydrogen atoms influence the electronic stability of the lactone group. The effect of the locations of the hydroxyl groups may be explained by assuming that the lactone structure is stabilized by the formation of hydrogen bonds between the protons of hydroxyl groups and the carbonyl oxygen. Supposedly the hydroxyl on carbon 2 forms a hydrogen bond with the carbonyl oxygen; when the hydroxyl of either carbon 3 or carbon 5 (or both) lies on the same side of the ring as the hydroxyl of carbon 2, the hydrogen of either of these hydroxyls (or both) would also be attracted to the negative carbonyl oxygen and would tend further to stabilize the lactone group. But if the hydroxyls of carbons 3 and 5 lie on the opposite side of the ring from the hydroxyl of carbon 2 , the attraction of their protons for the carbonyl oxygen would be exerted in the opposite direction and would tend to weaken the lactone structure. Furthermore, the hydroxyls of carbons 2 and 5 are in more favorable positions for coordination with the carbonyl oxygen than the hydroxyl of carbon 3 , and hence their relative positions in space would be of more importance than the position of the hydroxyl of carbon 3 in determining the stability of the lactone. In agreement with this concept, the highest reduction potentials are obtained when the hydroxyls of carbons 2,3 , and 5 all lie on the same side of the ring, and hence in favorable positions for coordination with the carbonyl oxygen. The next highest reduction potentials are obtained when the hydroxyls of carbons 2 and 5 are favorably located, and the lowest reduction potentials are obtained when the hydroxyl of carbon 2 is on one side of the lactone ring and the hydroxyls of carbons 3 and 5 are on the other side.

\section{CHARACTERISTIC FEATURES OF THE POLAROGRAMS FOR THE VARIOUS SUBSTANCES}

Since only a few of the polarograms made in the course of this investigation can be reproduced in this paper, an attempt has been made to describe briefly the characteristic features of the curves obtained. In comparing the results it should be remembered that the lower 
acids - glycolic, lactic, and glyceric - do not form lactones but form condensation products of the lactyllactic acid and lactide types. They also form more complex polymers which have not been included in the present investigation. The tetronic acids form stable gamma lactones and show little tendency to form condensation products of the lactide and lactyllactic acid types. They differ from the higher aldonic acids in that they cannot form delta lactones and in that on carbon 4 they have two hydrogen atoms, symmetrically located with respect to the lactone ring, in place of a single hydrogen and a side chain. Although the pentonic acids are capable of forming delta lactones in addition to the gamma lactones and condensation products, the polarograms for the pentonic acids and their gamma lactones fail to show the presence of detectable quantities of delta lactones. In the methyl pentonic and hexonic groups, several delta lactones are known, and we have determined their polarographic behavior. Most of the compounds used in these measurements were prepared in the Bureau's laboratories by the methods cited in the reference given after the name of the compound; other sources of material are indicated in footnotes.

\section{GLYCOLIC ACID?}

A $0.01 M$ solution of glycolic acid in $0.1 M$ tetraethylammonium chloride showed only a -1.8-v hydrogen wave with a pointed maximum (fig. 2). During the course of 24 hours, the height of the wave increased from $53 \mathrm{~mm}$ to a maximum of $72 \mathrm{~mm}$. Since the increase in the hydrogen wave is evidence of a change in structure, it seems probable that part of the acid hydrogen in the freshly prepared solution is bound in some manner. In this connection, it is noteworthy that glycolic acid exists in two crystalline forms [9]; the one used in this investigation melts at $80^{\circ} \mathrm{C}$, the other melts at $63^{\circ} \mathrm{C}$. Ohle [10] has suggested that glycolic acid under suitable conditions exists in a dimolecular state represented by the following formula:

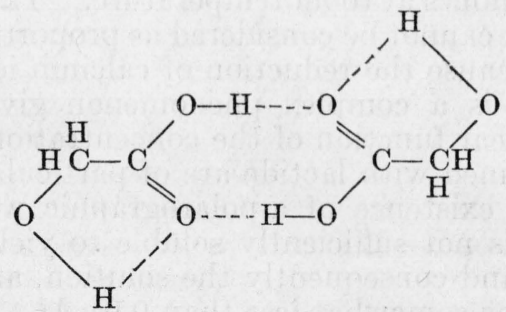

A substance having this structure would yield acidic groups on splitting and account for the observed increase in the hydrogen wave.

The solution of glycolic acid after long standing gave a small wave at $-2.8 \mathrm{v}$ which appears to be analogous to a similar wave found for lactic acid.

\section{LACTIC ACID, LACTYLLACTIC ACID, AND LACTIDE}

The practical and theoretical importance of lactic acid and its derivatives led to the study of lithium lactate [11], lactic acid liberated from

- The glycolic acid was purchased from A. D. Mackay, New York, N. Y. 
calcium $d$-lactate ${ }^{10}$ commercial lactic acid containing lactyllactic acid [12], and lactide [13] (fig. 7).

The polarograms of $0.01 M$ lithium lactate in $0.1 M$ tetraethylammonium chloride showed only a lithium wave at $-2.44 \mathrm{v}, 46$ to $48 \mathrm{~mm}$ high, with a small pointed maximum. The absence of other waves shows that the lactate ion is not reduced under the conditions used. Measurements were made with lactic acid, freshly prepared from calcium $d$-lactate by the addition of an equivalent quantity of oxalic acid, to compare with measurements made with commercial lactic acid after dilution with water. Except for the effect of traces of calcium arising from the solubility of calcium oxalate, there was no significant difference between the polarograms for the commercial acid and those for the acid liberated from calcium $d$-lactate. As shown in figure 7 , the freshly mixed solutions showed hydrogen waves 53 and $52 \mathrm{~mm}$ high, which decreased in the course of 453 hours at room temperature to 9 and $17 \mathrm{~mm}$, respectively. At least a portion of this decrease in acid concentration was associated with the appearance of wave $A$, which after 453 hours had grown to 9 and $8 \mathrm{~mm}$.

After 200 hours there appeared in polarograms of both solutions evidence of a wave at about $-2.85 \mathrm{v}$. After 453 hours this wave was $15 \mathrm{~mm}$ high at $-2.85 \mathrm{v}$ in the solution which contained originally calcium $d$-lactate, and about $40 \mathrm{~mm}$ high at $-2.80 \mathrm{v}$ in the solution which contained originally commercial lactic acid. This wave, which appears analogous to that observed with glycolic acid, cannot be ascribed to the lactyllactic acid linkage unless its reduction potential is markedly a function of $\mathrm{pH}$ and was, as a result, masked in the earlier polarograms by the reduction of the tetraethylammonium ion present in the supporting electrolyte.

Another interesting feature of the study of these two solutions was the behavior of the wave at $-2.40 \mathrm{v}$, due to calcium ion. Although the solution was stirred only for a short time immediately preceding the taking of each polarogram, it is surprising that aging of the precipitated calcium oxalate, as indicated by the change in its solubility, should require 300 hours at room temperature. The magnitude of the change in solubility cannot be considered as proportional to the change in wave height, because the reduction of calcium ion at the dropping mercury electrode is a complex phenomenon giving rise to waves which are not a linear function of the concentration [14].

The results obtained with lactide are of particular interest because they establish the existence of a polarographic wave for the lactide linkage. Lactide is not sufficiently soluble to yield rapidly a $0.1 M$ aqueous solution, and consequently the solution, after dilution in the electrode vessel, was somewhat less than $0.01 M$. Although the first polarogram (fig. 2) was begun only 7 minutes after the compound was wet with water, hydrolysis had already proceeded sufficiently to show a hydrogen wave $5 \mathrm{~mm}$ high at $-1.72 \mathrm{v}$. This wave was followed by a single wave, or a pair of partially merged waves, which rose slowly to a diffusion current. This rise occupied the region from -1.9 to $-2.4 \mathrm{v}$. If these are separate waves, they have inflection points at -2.03 and $-2.22 \mathrm{v}$, and heights of 12 and $9 \mathrm{~mm}$, respectively. They decreased in height rapidly and disappeared completely in 24 hours. Hence at equilibrium there is little or no lactide present.

10 The calcium $d$-lactate was furnished by George Ward, Bureau of Agricultural Chemistry and Engineering, U. S. Department of Agriculture, 
During the first 24 hours the hydrogen wave increased to a maximum of $41 \mathrm{~mm}$ and decreased slowly thereafter. The pronounced maximum associated with the hydrogen wave of lactic acid prepared from both calcium $d$-lactate and commercial lactic acid was not observed in the polarogram of the acid obtained from lactide. Wave $A$ and the $-2.8-\mathrm{v}$ wave given by lactic acid failed to appear.

\section{GLYCERIC ACID 11}

The freshly prepared solution of glyceric acid showed only the hydrogen wave with a pointed maximum (fig. 2) and an inflection point estimated to be at $-1.81 \mathrm{v}$. During the course of 24 hours, the height of this wave increased from $50 \mathrm{~mm}$ to $53 \mathrm{~mm}$. This increase, although small, may be analogous to the increase noted for glycolic acid and may be caused by the same type of reaction. The polarogram for the freshly prepared solution of glyceric acid also revealed a pointed maximum at $-2.75 \mathrm{v}$, about $12 \mathrm{~mm}$ high, which did not change appreciably on standing. This maximum may have been caused by an impurity or by a condensation product, such as glycerylglyceric acid. After 453 hours, wave $A$ appeared, $2 \mathrm{~mm}$ high, while the hydrogen wave had decreased to $26 \mathrm{~mm}$.

\section{4. $d$-ERYTHRONO- $\gamma$-LACTONE 12}

A $0.01 M$ solution of $d$-erythrono- $\gamma$-lactone in $0.1 M$ tetraethylammonium chloride gave a wave 60 to $70 \mathrm{~mm}$ high, with an inflection point at $-2.65 \mathrm{v}$, which changed very little in the course of 457 hours. A small hydrogen wave at $-1.70 \mathrm{v}$ appeared after about 96 hours and grew in the course of 457 hours to a height of $4 \mathrm{~mm}$.

\section{1-THREONO- $\gamma$-LACTONE ${ }^{13}$}

The polarographic curve obtained with a $0.01 \mathrm{M}$ solution of $l$ threono- $\gamma$-lactone in $0.1 M$ tetraethylammonium chloride (fig. 2) was similar to that obtained with $d$-erythrono- $\gamma$-lactone except that the lactone wave appeared at $-2.54 \mathrm{v}$ with a small rounded maximum instead of at $-2.65 \mathrm{v}$. After 453 hours the hydrogen wave had not appeared but wave $A, 1 \mathrm{~mm}$ high, was present at $-1.13 \mathrm{v}$. This shows that a part of the lactone had been hydrolyzed and utilized in the "oxygen-mercury" reaction.

\section{1-ARABONO- $\gamma$-LACTONE [15]}

A $0.01 M$ solution of $l$-arabono- $\gamma$-lactone in $0.1 M$ tetraethylammonium chloride gave a wave $60 \mathrm{~mm}$ high at $-2.60 \mathrm{v}$, which decreased to $40 \mathrm{~mm}$ in 457 hours. In the course of 28 hours, a hydrogen wave $1 \mathrm{~mm}$ high appeared at $-1.74 \mathrm{v}$. There is no evidence of the formation of a wave which could be ascribed to the delta lactone. After 120 hours, wave $A$ appeared at $-1.13 \mathrm{v}$, at the expense of the hydrogen wave.

11 The glyceric acid used in the investigation was a commercial liquid product from the firm of C. A. F. Kahlbaum.

The crystalline lactone was furnished by J. E. Glattfeld, University of Chicago.

13 The crystalline lactone was furnished by Chas. Pfizer \& Co. 


\section{1-RIBONO- $\gamma$-LACTONE [16]}

A $0.01 M$ freshly prepared solution of $l$-ribono- $\gamma$-lactone in $0.1 M$ tetraethylammonium chloride gave a wave $61 \mathrm{~mm}$ high with a rounded maximum at $-2.44 \mathrm{v}$. In the course of 457 hours, the wave decreased to $40 \mathrm{~mm}$ without a maximum while a hydrogen wave $2 \mathrm{~mm}$ high appeared at -1.80 v. After 193 hours a very small wave $A$ at $-1.2 \mathrm{v}$ was present.

\section{8. $d$-XYLONO- $\gamma$-LACTONE [5]}

A freshly prepared $0.01 M$ solution of $d$-xylono- $\gamma$-lactone in $0.1 M$ tetraethylammonium chloride (fig. 8) gave a wave at $-2.48 \mathrm{v}, 68 \mathrm{~mm}$ high, which decreased in 453 hours to $18 \mathrm{~mm}$. As this wave became smaller, its inflection point shifted to more negative values, reaching $-2.56 \mathrm{v}$ in 453 hours. In the course of 24 hours, a hydrogen wave appeared at $-1.76 \mathrm{v}$, and reached a height of $20 \mathrm{~mm}$ in 194 hours, when it appeared to be the result of the merging of two waves of approximately equal heights. Wave $A$ appeared at $-1.1 \mathrm{v}$ in the course of about 100 hours and increased to a height of $7 \mathrm{~mm}$ in 453 hours.

\section{9. $d$-LYXONO- $\gamma$-LACTONE [17]}

A freshly prepared $0.01 M$ solution of $d$-lyxono- $\gamma$-lactone in $0.1 M$ tetraethylammonium chloride showed a single large wave with a very erratic diffusion current. The inflection point was estimated to be at $-2.6 \mathrm{v}$ and the height about $60 \mathrm{~mm}$. Close examination of the initial current increase indicated the possible presence of a wave several $\mathrm{mm}$ high at $-2.3 \mathrm{v}$. The presence of this small wave became more obvious in polarograms taken at later times, but even after 453 hours it was not clearly separated from the beginning of the lactone wave. After 453 hours the lactone wave had decreased to a height of about $30 \mathrm{~mm}$. A hydrogen wave, as such, failed to appear although hydrolysis of the lactone must have occurred, since wave $A$ appeared 139 hours after mixing the solution and at 453 hours had become $2 \mathrm{~mm}$ high. The curves obtained were much like those from $d$-gulono- $\gamma$-lactone except for the more erratic diffusion current.

\section{1-RHAMNONO-LACTONES [15]}

The polarogram of a freshly prepared $0.01 \mathrm{M}$ solution of $l$-rhamnono- $\delta$-lactone in $0.05 M$ lithium chloride showed a wave about 60 $\mathrm{mm}$ high at $-2.15 \mathrm{v}$. This wave disappeared in the course of 24 hours, and a hydrogen wave appeared at $-1.77 \mathrm{v}$. The latter wave reached a height of $45 \mathrm{~mm}$ in 24 hours and did not change further in 235 hours.

A freshly prepared $0.01 M$ solution of $l$-rhamnono- $\delta$-lactone in $0.1 M$ tetraethylammonium chloride (fig. 8) gave a lactone wave at $-2.30 \mathrm{v}$ with a rounded maximum and a diffusion current corresponding to a height of about $35 \mathrm{~mm}$. The lactone wave disappeared in the course of 21 hours, and a hydrogen wave appeared at $-1.80 \mathrm{v}$. Obviously the delta lactone is hydrolyzed rapidly, and the equilibrium state for the acid-lactone mixture does not contain an appreciable quantity of the delta lactone. In the course of time the hydrogen wave developed a maximum and passed through the stages described more fully on page 103, and shown in figure 8 . The hydrogen 


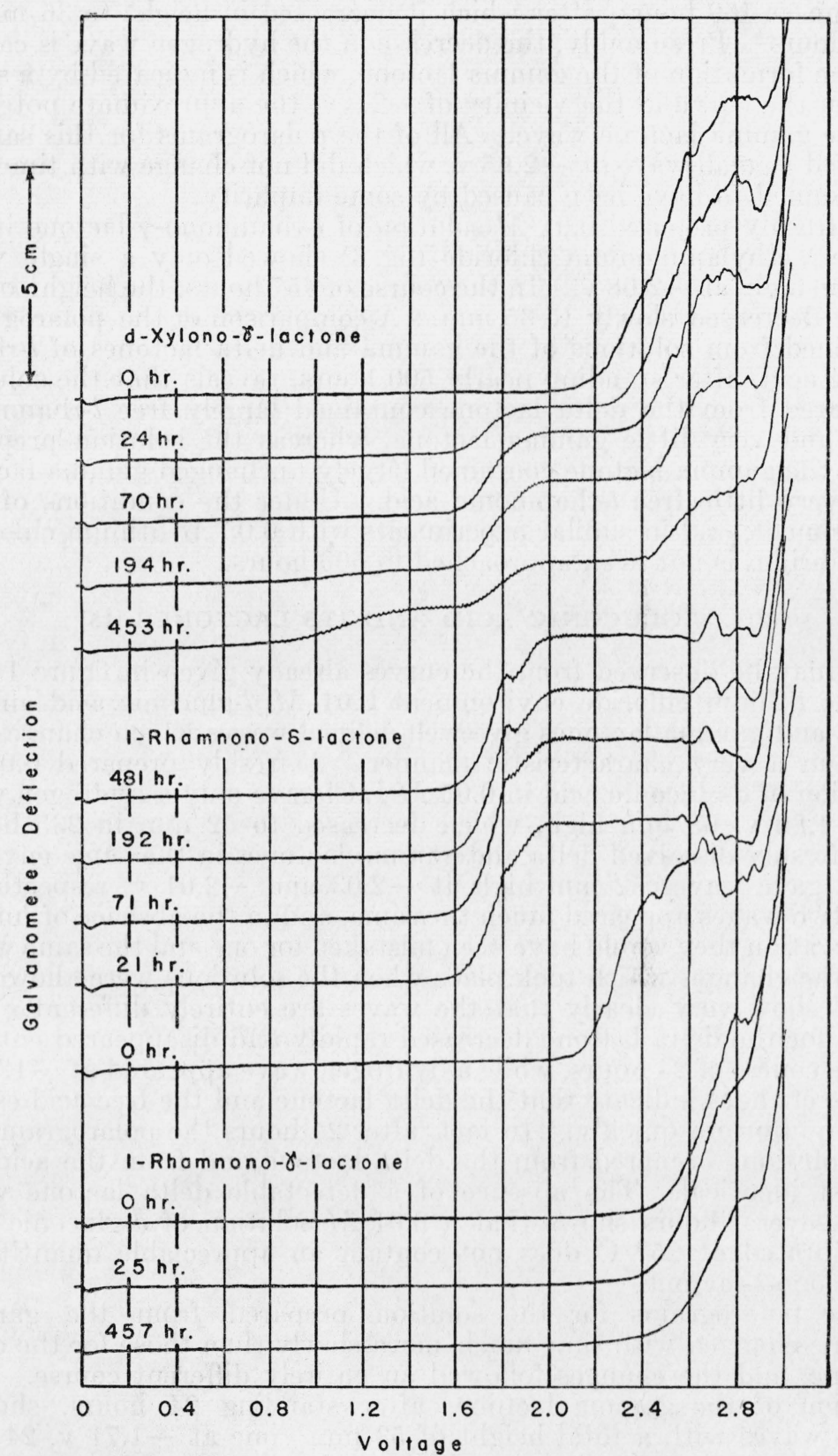

Figure 8.-Polarograms which show the effect of time upon $0.01 M$ solutions of $d$-xylono- $\gamma$-lactone, l-rhamnono- $\delta$-lactone, and l-rhamnono- $\gamma$-lactone in $0.1 M$ tetraethylammonium chloride. 
wave was $37 \mathrm{~mm}$ high at 21 hours and reached a maximum height of $39 \mathrm{~mm}$ at 169 hours, after which it decreased in height to $36 \mathrm{~mm}$ at 481 hours. Presumably, the decrease in the hydrogen wave is caused by the formation of the gamma lactone, which is indicated by a small rise in the curve in the vicinity of $-2.8 \mathrm{v}$, the approximate potential of the gamma lactone wave. All of the polarograms for this sample showed a small wave at $-2.65 \mathrm{v}$, which did not change with time and is assumed to have been caused by some impurity.

A fresbly prepared $0.01 M$ solution of $l$-rhamnono- $\gamma$-lactone in 0.1 $M$ tetraethylammonium chloride (fig. 8) showed only a single wave $45 \mathrm{~mm}$ high, at $-2.68 \mathrm{v}$. In the course of 457 hours, the height of the wave decreased slowly to $35 \mathrm{~mm}$. A comparison of the polarograms obtained from solutions of the gamma and delta lactones of $l$-rhamnonic acid, after standing nearly 500 hours, reveals that the solution prepared from the delta lactone contained largely free $l$-rhamnonic acid and very little gamma lactone, whereas the solution prepared from the gamma lactone contained largely unchanged gamma lactone and very little free $l$-rhamnonic acid. Under the conditions of this experiment, and in similar experiments with $0.05 M$ lithium chloride, equilibrium is not even approached in 500 hours.

\section{1. $d$-GLUCONIC ACID AND ITS LACTONES [15]}

It may be observed from the curves already given in figure 1 that in the lithium chloride environment $0.01 M d$-gluconic acid and its delta and gamma lactones give well-defined waves which change with time in a very characteristic manner. A freshly prepared $0.01 M$ solution of $d$-gluconic acid in $0.05 \mathrm{M} \mathrm{LiCl}$ gave only a hydrogen wave at $-1.80 \mathrm{v}, 68 \mathrm{~mm}$ high, which decreased to $52 \mathrm{~mm}$ in 235 hours. The freshly dissolved delta and gamma lactones in the same environment gave waves $52 \mathrm{~mm}$ high at -2.03 and $-2.01 \mathrm{v}$, respectively. The two waves appeared much the same, and in the absence of further observation they would have been mistaken for one and the same wave. But the changes which took place when the solutions were allowed to stand show very clearly that the waves are entirely different. The wave for the delta lactone decreased rapidly and disappeared entirely in the course of 24 hours, while a hydrogen wave appeared at $-1.77 \mathrm{v}$. These changes indicate that the delta lactone and the free acid establish equilibrium quickly. In fact, after 24 hours the polarograms for the solutions prepared from the delta lactone and from the acid are almost identical. The absence of a detectable delta lactone wave after several hours shows that a $0.01 M$ solution of $d$-gluconic acid equilibrated at $25^{\circ} \mathrm{C}$ does not contain an appreciable quantity of $d$-glucono- $\delta$-lactone.

The polarograms for the solution prepared from the gamma lactone changed with time much more slowly than those for the delta lactone, and the changes followed an entirely different course. The solution of the gamma lactone, after standing 24 hours, showed three waves with a total height of $53 \mathrm{~mm}-$ one at $-1.71 \mathrm{v}, 24 \mathrm{~mm}$ high; one at $-2.08 \mathrm{v}, 4 \mathrm{~mm}$ high; and one at $-2.22 \mathrm{v}, 25 \mathrm{~mm}$ high. The $-1.71-v$ hydrogen wave may be attributed to the acid set free by hydrolysis of the lactone and needs no further explanation; but the presence of two waves in the region originally 
occupied by the gamma lactone wave requires consideration. The $-2.22-\mathrm{v}$ wave may be assigned to the gamma lactone, because measurements at frequent intervals during a 235 -hour period revealed a gradual decrease in the height of the wave and a movement towards a more negative potential. This shift in potential of the wave may be caused by the change in the environment incident to the increase in acidity. The small wave at $-2.08 \mathrm{v}$ (which moved to $-2.03 \mathrm{v}$ before disappearing) may be caused by a condensation product or other substance produced from the gamma lactone during the course of the hydrolysis. The reality of the $-2.08-\mathrm{v}$ wave is supported by the existence of similar waves in the polarograms obtained by using the tetraethylammonium chloride environment. When the solution was allowed to stand, the $-2.08-v$ wave decreased in height and disappeared completely in about 120 hours. This shows that the concentration of the substance, whatever it may be, decreases until at equilibrium it is scarcely detectable. In the polarogram obtained at 235 hours, the gamma lactone wave is detectable but poorly defined and about $3 \mathrm{~mm}$ high, and the hydrogen wave is about $43 \mathrm{~mm}$ high. Thus it appears that the $0.01 M$ equilibrated solution of $d$-glucono- $\gamma$ lactone contains for the most part the free acid with a small quantity of the gamma lactone and very little, if any, delta lactone.

As may be seen by comparing the curves of figures $1,4,5$, and 9 , the polarograms for $d$-gluconic acid and its lactones in the tetraethylammonium chloride environment are similar to those obtained in the presence of lithium chloride, but differ from the latter as the waves appear at slightly more negative potentials and usually show pointed maxima and erratic diffusion currents.

A freshly prepared $0.01 M$ solution of $d$-gluconic acid in $0.1 M$ tetraethylammonium chloride (fig. 9) showed only a $-1.80-\mathrm{v}$ hydrogen wave about $55 \mathrm{~mm}$ high, with a pointed maximum. The height of the hydrogen wave decreased in the course of 457 hours to $12 \mathrm{~mm}$. Probably because the maximum decreased more rapidly than the diffusion current, this hydrogen wave appeared, after 193 hours, to be two partially merged waves; but at 457 hours it appeared quite normal. Wave $A$ at $-1.12 \mathrm{v}$, first detected at 48 hours, increased in height to $7 \mathrm{~mm}$ at 457 hours. At 457 hours a small rounded maximum appeared at $-2.35 \mathrm{v}$ and seemed to indicate a small wave, probably due to $d$-glucono- $\gamma$-lactone.

A $0.01 M$ solution of $d$-glucono- $\delta$-lactone in $0.1 M$ tetraethylammonium chloride (fig. 9), 6 minutes after mixing, gave a wave at $-2.16 \mathrm{v}, 33 \mathrm{~mm}$ high, which appeared to have a rounded maximum partly merged with a wave at about $-2.33 \mathrm{v}$, perhaps $7 \mathrm{~mm}$ high, rising slowly to the diffusion current. It may be that the two waves are parts of a single wave consisting of a maximum superposed on the inflection point. The delta lactone in the dilute aqueous solution was hydrolyzed rapidly, as shown by the presence of a small hydrogen wave at $-1.73 \mathrm{v}$ only 6.5 minutes after the lactone was dissolved, and by the fact that the polarogram at the end of $3 \frac{1}{2}$ hours was substantially identical with that of a similar freshly prepared solution of $d$-gluconic acid in the same environment.

A $0.01 M$ freshly prepared solution of $d$-glucono- $\gamma$-lactone in $0.1 M$ tetraethylammonium chloride (fig. 9) showed only a wave at $-2.16 \mathrm{v}$, $40 \mathrm{~mm}$ high. After 4.5 hours the wave was unchanged; in 27 hours it had decreased to $33 \mathrm{~mm}$ and continued to decrease until at 457 hours 


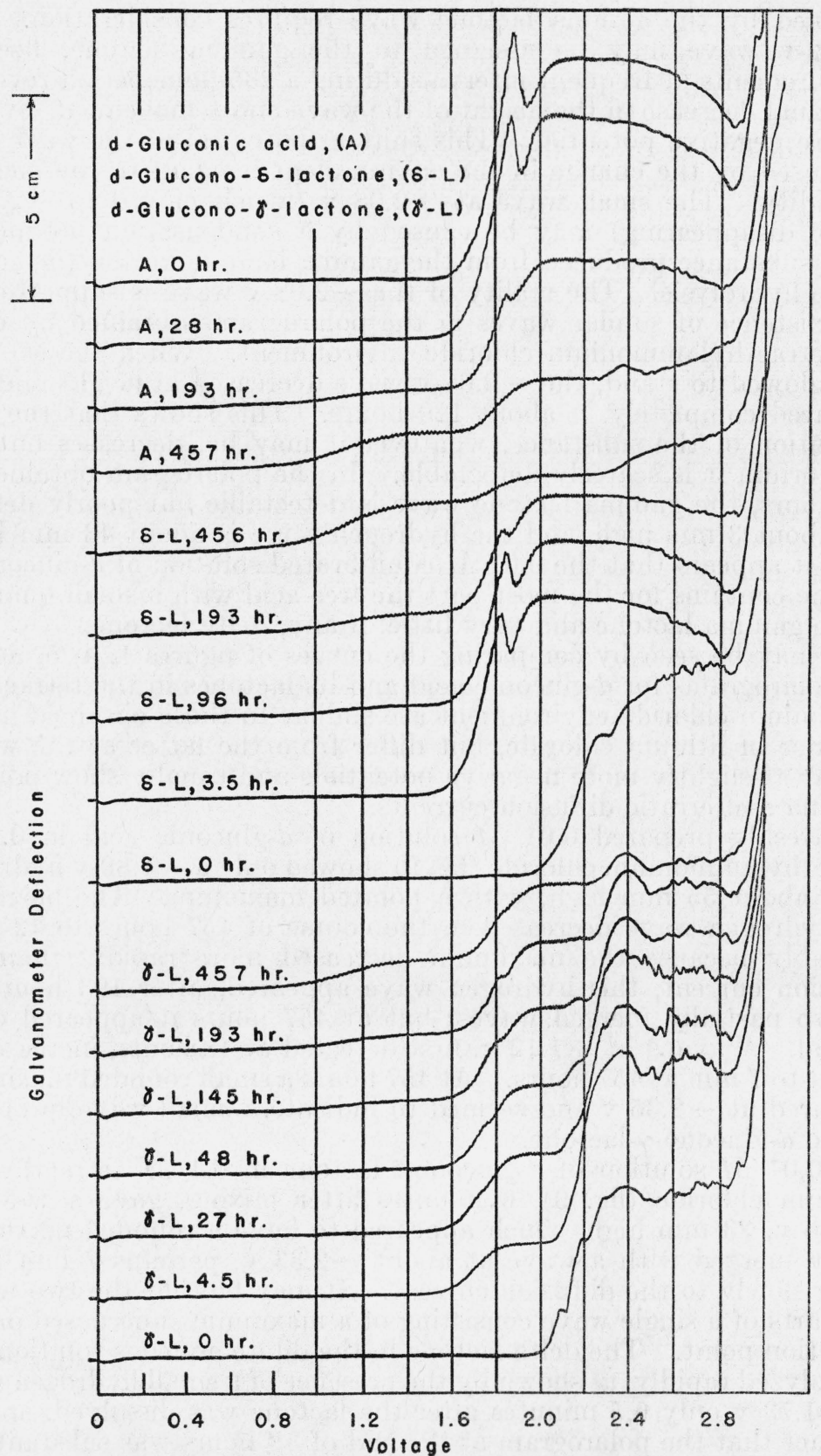

Figure 9.-Polarograms for d-gluconic acid, d-glucono- $\delta$-lactone, and d-glucono- $\gamma$ lactone, $0.01 \mathrm{M}$, in $0.1 \mathrm{M}$ tetraethylammonium chloride.

The curves for the lactones are not strictly comparable with those of figures 4 and 5 because different capillaries were used in the two cases. 
it showed only as a rounded maximum $5 \mathrm{~mm}$ high without an appreciable diffusion current. At 48 hours this wave appeared to have moved from -2.16 to $-2.25 \mathrm{v}$, while a definite wave $6 \mathrm{~mm}$ high became visible at $-2.12 \mathrm{v}$. The shift in the potential of the gamma lactone wave and the appearance of a new wave at a slightly less negative potential parallels the changes which were found in the polarograms obtained with lithium chloride environmental solutions. The $-2.2-\mathrm{v}$ lactone wave gradually decreased and was scarcely detectable at 193 hours. It may well be that the $-2.16-v$ wave found in the freshly prepared solution is composed of two waves at -2.12 and $-2.25 \mathrm{v}$ which are resolvable as they become smaller. The hydrogen wave appeared shortly after the solution was prepared; at 4.5 hours it was $12 \mathrm{~mm}$ high at $-1.72 \mathrm{v}$; at 27 hours it was $18 \mathrm{~mm}$ high and appeared to be composed of two waves, partly merged, at -1.70 and $-1.82 \mathrm{v}$. At 48 hours the composite wave was unchanged in appearance and $20 \mathrm{~mm}$ high; it decreased to $18 \mathrm{~mm}$ at 457 hours and still gave the appearance of a pair of partially merged waves. Wave $A$ appeared at 145 hours and increased to $10 \mathrm{~mm}$ at 457 hours. The results clearly show that $d$-glucono- $\gamma$-lactone is hydrolyzed less rapidly than d-glucono- $\delta$-lactone, but more rapidly than any of the other gamma lactones studied.

\section{2. d-GALACTONIC ACID AND ITS GAMMA LACTONE [15]}

The polarogram obtained with a freshly prepared $0.01 M$ solution of crystalline anhydrous $d$-galactonic acid in $0.1 M$ tetraethylammonium chloride (fig. 10) showed only a $-1.80-\mathrm{v}$ hydrogen wave, $64 \mathrm{~mm}$ high, with a pointed maximum. In the course of 167 bours the hydrogen wave decreased, and the maximum was suppressed so as to give the effect of two waves. After 456 hours, the free acid appeared to have been entirely neutralized, and the hydrogen wave had been replaced by wave $A$ at $-1.1 \mathrm{v}, 6 \mathrm{~mm}$ high. In addition to wave $A$, there appeared to be a wave at $-2.28 \mathrm{v}$, with a rounded maximum, and also a poorly developed wave about $20 \mathrm{~mm}$ high at $-2.66 \mathrm{v}$. The latter matched the wave for $d$-galactono- $\gamma$-lactone and was probably caused by that substance. The results indicate that a $0.01 M$ solution of $d$-galactonic acid at equilibrium contains an appreciable quantity of the gamma lactone, and perhaps an unidentified substance.

The polarogram for a freshly prepared $0.01 M$ solution of $d$ galactono- $\gamma$-lactone in $0.1 M$ tetraethylammonium chloride (fig. 10) gave a wave $36 \mathrm{~mm}$ high at $-2.62 \mathrm{v}$ and also a very small wave at $-2.15 \mathrm{v}$. The latter wave, which was perhaps $2 \mathrm{~mm}$ high, was noticeable in the polarogram taken after 24 hours but disappeared in the course of 48 hours. Possibly this wave was caused by the presence of a small quantity of impurity in the sample. The gamma lactone wave at $-2.62 \mathrm{v}$ decreased in the course of 452 hours to $25 \mathrm{~mm}$. A small hydrogen wave at $-1.70 \mathrm{v}$ appeared in the polarograms taken from 48 to 191 hours after preparation of the solution, and was absent at 452 hours. The disappearance of the hydrogen wave may be attributed to the neutralizing action of the mercury in the presence of traces of oxygen, since wave $A$ appeared at 452 hours, $2 \mathrm{~mm}$ high. 


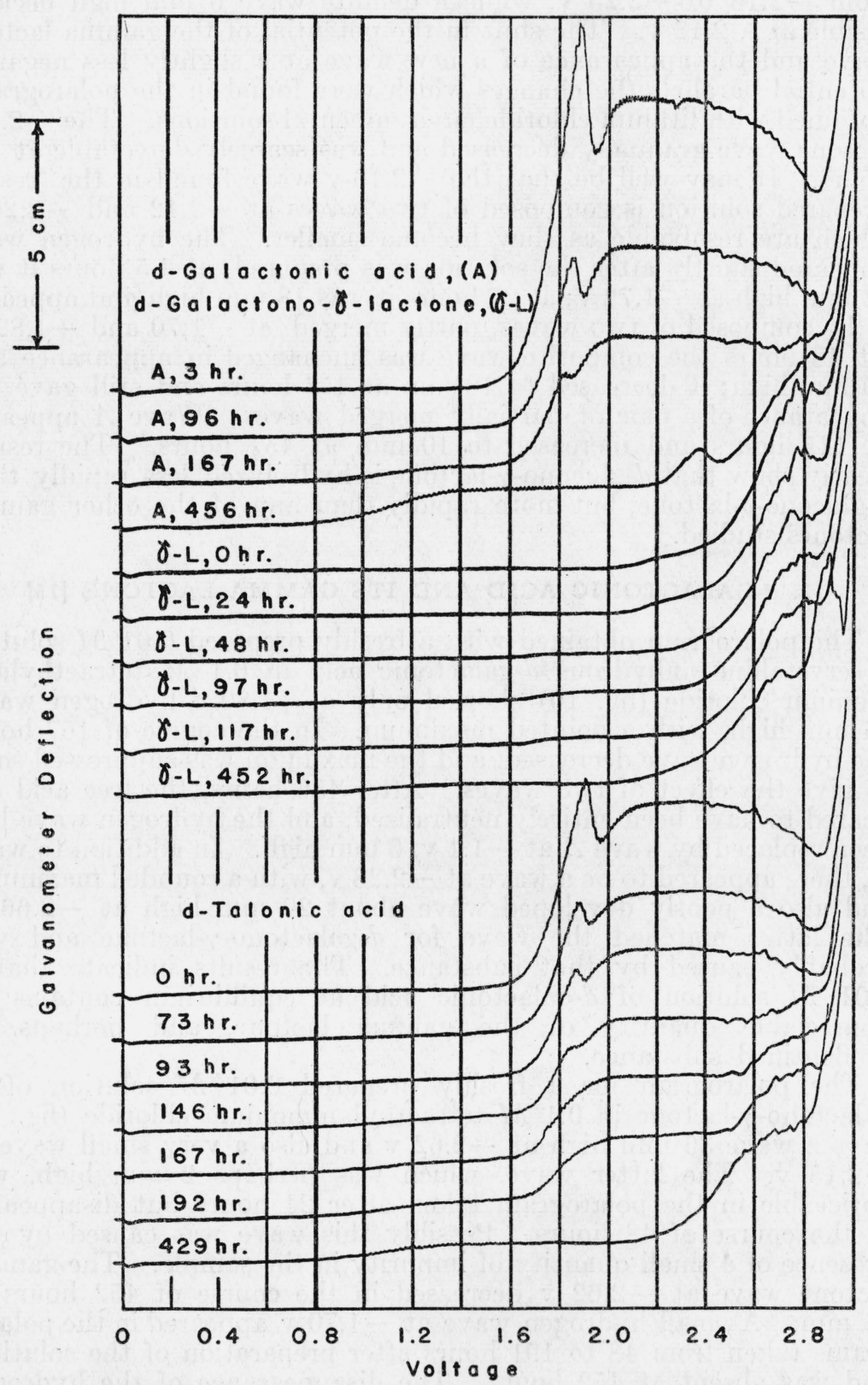

Figure 10.--Polarograms which show the effect of time on solutions of $0.01 \mathrm{M}$ $d$-galactonic acid, d-galactono- $\gamma$-lactone, and d-talonic acid in $0.1 \mathrm{M}$ tetraethylammonium chloride. 


\section{3. d-MANNONO-LACTONES [15]}

The polarogram for a freshly prepared $0.01 M$ solution of $d$-mannono- $\delta$-lactone in $0.1 M$ tetraethylammonium chloride gave a single wave approximately $50 \mathrm{~mm}$ high at about $-2.4 \mathrm{v}$. After 1.3 hours this delta lactone wave had not changed appreciably and there was no evidence of the hydrogen wave, but after 24 hours the solution gave the hydrogen wave at $-1.75 \mathrm{v}, 23 \mathrm{~mm}$ high, and the delta lactone wave had entirely disappeared. Apparently, even at $25^{\circ} \mathrm{C}$ the delta lactone in $0.01 M$ solution is hydrolyzed in the course of 24 hours and is not present in detectable quantity in the equilibrated solution. The lack of a hydrogen wave in the polarogram taken after 1.3 hours shows that hydrolysis begins slowly, as might be expected in a neutral solution. A wave, supposedly caused by the gamma lactone, appeared at $-2.60 \mathrm{v}$, and reached a height of 12 $\mathrm{mm}$ in 429 hours.

The polarogram for the freshly prepared $0.01 \mathrm{M}$ solution of $d$ mannono- $\gamma$-lactone in $0.1 \mathrm{M}$ tetraethylammonium chloride showed a wave $50 \mathrm{~mm}$ high at $-2.65 \mathrm{v}$. When the solution was allowed to stand, the lactone wave did not change appreciably in spite of the fact that after 48 hours a small hydrogen wave appeared at -1.74 to $-1.78 \mathrm{v}$ and increased to a height of $3 \mathrm{~mm}$ in 451 hours.

\section{4. d-TALONIC ACID AND ITS GAMMA LACTONE [18]}

The polarograms for $d$-talonic acid in $0.1 M$ tetraethylammonium chloride (fig. 10) show that, even in dilute aqueous solution, the free acid changes relatively quickly into the corresponding lactone. A freshly prepared $0.01 M$ solution of $d$-talonic acid gave only a single wave (with pointed maximum) at $-1.82 \mathrm{v}, 40 \mathrm{~mm}$ high. When the solution was allowed to stand, the heights of both the wave and the maximum decreased, the latter more rapidly than the former, so that at 146 hours the wave had the appearance of two partially merged waves. At 167 hours the acid wave had decreased to $17 \mathrm{~mm}$ and a wave (supposedly caused by the gamma lactone) had appeared at $-2.6 \mathrm{v}, 8 \mathrm{~mm}$ high. At 429 hours the acid wave had disappeared entirely and the lactone wave had increased to a height of $24 \mathrm{~mm}$ and had shifted to $-2.48 \mathrm{v}$. In addition to the waves enumerated, wave $A$ appeared in the course of 146 hours and increased to a height of $3 \mathrm{~mm}$ at 429 hours. As mentioned before, wave $A$ indicates a reaction between dissolved oxygen, mercury, and the sugar acid.

A freshly prepared $0.01 M$ solution of $d$-talono- $\gamma$-lactone in 0.1 $M$ tetraethylammonium chloride gave only a single wave with a very high sharp maximum which in a less readily reduced environment would have shown a diffusion current perhaps $50 \mathrm{~mm}$ high with an inflection point at about $-2.5 \mathrm{v}$. The lactone wave did not change markedly with time, but after 24 hours a small hydrogen wave appeared at $-1.75 \mathrm{v}$ and at 429 hours had increased to $8 \mathrm{~mm}$. On account of a very erratic diffusion current, the height of the $\gamma$-lactone wave could not be estimated.

\section{5. $d$-GULONO- $\gamma$-LACTONE [19]}

The polarogram obtained with a freshly prepared $0.01 M$ solution of $d$-gulono- $\gamma$-lactone in $0.1 M$ tetraethylammonium chloride showed only a wave at $-2.60 \mathrm{v}$. For the first 117 hours the height of this 
lactone wave was of the order of $50 \mathrm{~mm}$, after which it decreased slowly to $38 \mathrm{~mm}$ at 453 hours. Wave $A$ at $-1.15 \mathrm{v}$ was first noticeable at 117 hours and increased slowly to $1 \mathrm{~mm}$ at 453 hours. The marked stability of this lactone is shown by the absence of the hydrogen wave in the polarograms obtained over a long period of time. However, the decrease in height of the lactone wave and the appearance of wave $A$ show that some hydrolysis of the lactone occurred.

\section{1-ALLONO- $\gamma$-LACTONE [20]}

The polarogram for a freshly prepared $0.01 M$ solution of $l$-allono$\gamma$-lactone in $0.1 M$ tetraethylammonium chloride gave only a wave at $-2.52 \mathrm{v}, 58 \mathrm{~mm}$ high, which decreased to $43 \mathrm{~mm}$ in 453 hours. A hydrogen wave at $-1.75 \mathrm{v}$ appeared shortly after the lactone was dissolved; it was $4 \mathrm{~mm}$ high in 24 hours and increased to $11 \mathrm{~mm}$ in 453 hours.

\section{7. $d$ - $\alpha$-GALAHEPTONO- $\gamma$-LACTONE [21]}

A freshly prepared $0.01 M$ solution of $d$ - $\alpha$-galaheptono- $\gamma$-lactone in $0.1 M$ tetraethylammonium chloride showed only a wave starting at $-2.5 \mathrm{v}$ and rising very irregularly off scale. At 25 hours there was an irregular diffusion current with a wave height of $45 \mathrm{~mm}$ and an inflection point at approximately $-2.65 \mathrm{v}$. The compound is configurationally related to $l$-mannono- $\gamma$-lactone and resembles it in stability towards hydrolysis. The height of the lactone wave did not change appreciably in 457 hours, although a hydrogen wave approximately $1 \mathrm{~mm}$ high appeared at $-1.78 \mathrm{v}$.

\section{8. $d$ - $\alpha$-GLUCOHEPTONO- $\gamma$-LACTONE [22]}

A freshly prepared $0.01 M$ solution of $d$ - $\alpha$-glucoheptono- $\gamma$-lactone in $0.1 M$ tetraethylammonium chloride (fig. 11) gave a single wave at $-2.56 \mathrm{v}$, about $45 \mathrm{~mm}$ high. The $-2.56-\mathrm{v}$ wave appeared to start with a slow rise in current at $-2.2 \mathrm{v}$. In the course of time, this early rise was resolved into a wave at $-2.3 \mathrm{v}$ with a maximum and a diffusion current of about $5 \mathrm{~mm}$. Simultaneously the potential for the $-2.56-\mathrm{v}$ wave shifted to $-2.64 \mathrm{v}$, and a $-1.72-\mathrm{v}$ hydrogen wave appeared and grew in 459 hours to a height of $13 \mathrm{~mm}$. The cause of the wave at $-2.3 \mathrm{v}$ is not known, but it has been mentioned previously that many of the aldonic acids and lactones give small waves near this voltage. When these observations were repeated, using a freshly recrystallized sample and the constant-level capillary, the $-2.3-v$ wave failed to develop a maximum and the hydrogen wave, after appearing at 19 hours, was replaced by wave $A$.

\section{9. $d$ - $\beta$-GLUCOHEPTONO- $\gamma$-LACTONE [23]}

A freshly prepared $0.01 M$ solution of $d-\beta$-glucoheptono- $\gamma$-lactone in $0.1 M$ tetraethylammonium chloride showed only a single wave at $-2.53 \mathrm{v}$ about $57 \mathrm{~mm}$ high. In the course of 459 hours the inflection point of the wave shifted to $-2.57 \mathrm{v}$, and the height decreased to $47 \mathrm{~mm}$. Even on long standing the solution did not show a hydrogen wave, and hence the lactone is relatively stable towards hydrolysis. This stability seems peculiar inasmuch as the configuration of the lactone is similar to that of $d$-glucono- $\gamma$-lactone, which hydrolyzes readily. 


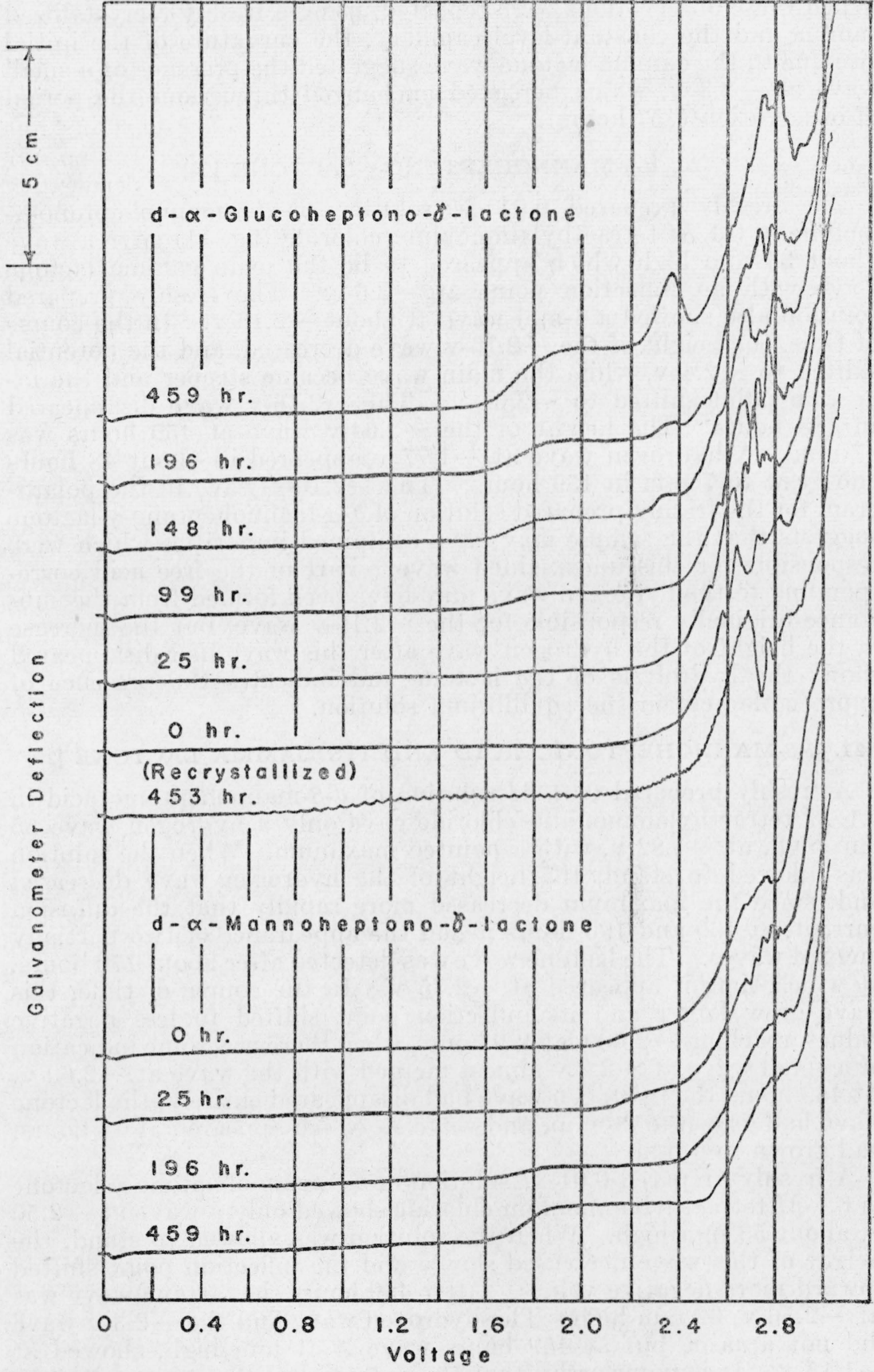

Figure 11.-Polarograms for $0.01 M d$ - $\alpha$-glucoheptono- $\gamma$-lactone and $d$ - $\alpha$-mannoheptono- $\gamma$-lactone in $0.1 \mathrm{M}$ tetraethylammonium chloride.

The recrystallized sample of $d$ - $\alpha$-glucoheptono- $\gamma$-lactone was run with the constant-level capillary. As a result the curve is comparable only qualitatively with the other curves of the group. 
When these observations were repeated, using a freshly recrystallized sample and the constant-level capillary, the curvature of the initial rise due to the gamma lactone wave suggested the presence of a small wave at $-2.3 \mathrm{v}$, which persisted unchanged throughout the period of observation (453 hours).

\section{0. $d$ - $\alpha$-MANNOHEPTONO- $\gamma$-LACTONE [24]}

The freshly prepared $0.01 M$ solution of $d$ - $\alpha$-mannoheptono- $\alpha$ lactone in $0.1 M$ tetraethylammonium chloride (fig. 11) gave a wave about $34 \mathrm{~mm}$ high which appeared to be the main gamma lactone wave with an inflection point at $-2.6 \mathrm{v}$. The freshly prepared solution also showed a $4-\mathrm{mm}$ wave at about $-2.16 \mathrm{v}$. In the course of time, the height of the $-2.16-\mathrm{v}$ wave decreased, and the potential shifted to $-2.4 \mathrm{v}$, while the main wave became steeper and the inflection point shifted to $-2.64 \mathrm{v}$. The $-2.16-\mathrm{v}$ wave disappeared in 168 hours. The height of the $-2.64-\mathrm{v}$ wave at 459 hours was $27 \mathrm{~mm}$. A hydrogen wave at $-1.77 \mathrm{v}$ appeared in about 48 hours and grew to $7 \mathrm{~mm}$ in 459 hours. The $-2.16-\mathrm{v}$ wave in the polarogram for the freshly prepared solution of $d-\alpha$-mannoheptono- $\gamma$-lactone suggests that the sample may have contained impurities which were responsible for this unexplained wave. Part of the free acid corresponding to the hydrogen wave may have been formed from the substance originally responsible for the $-2.16-\mathrm{v}$ wave, but the increase in the height of the hydrogen wave after this wave had disappeared shows the hydrolysis of the lactone and indicates the presence of appreciable acid in the equilibrium solution.

\section{1. $d-\beta$-MANNOHEPTONIC ACID AND ITS GAMMA LACTONE [25]}

A freshly prepared $0.01 M$ solution of $d$ - $\beta$-mannoheptonic acid in $0.1 M$ tetraethylammonium chloride gave only a hydrogen wave 55 $\mathrm{mm}$ high, at $-1.82 \mathrm{v}$, with a pointed maximum. When the solution was allowed to stand, the height of the hydrogen wave decreased and, since the maximum decreased more rapidly that the diffusion current, at 169 and 196 hours it had the appearance of two partially merged waves. The lactone wave was detected after about 170 hours, at which time it appeared at $-2.75 \mathrm{v}$. In the course of time, this wave grew larger and its inflection point shifted to less negative values, reaching $-2.60 \mathrm{v}$ at 429 hours, when there was some indication of a small wave at $-2.3 \mathrm{v}$ almost merged with the wave at $-2.60 \mathrm{v}$. At 459 hours the hydrogen wave had disappeared entirely, the lactone wave had grown to $26 \mathrm{~mm}$, and wave $A$, which appeared at 48 hours, had grown to $6 \mathrm{~mm}$.

A freshly prepared $0.01 \mathrm{M}$ solution of $d-\beta$-mannoheptono- $\gamma$-lactone in $0.1 M$ tetraethylammonium chloride showed only a wave at -2.50 $\mathrm{v}$, about $53 \mathrm{~mm}$ high. When the solution was allowed to stand, the height of this wave decreased slowly and the inflection point shifted toward more negative values. After 459 hours the lactone wave was at $-2.56 \mathrm{v}, 32 \mathrm{~mm}$ high. The hydrogen wave and the $-2.3-\mathrm{v}$ wave did not appear, but at 459 hours wave $A, 1 \mathrm{~mm}$ high, showed at $-1.15 \mathrm{v}$. It is noteworthy that the potential of the gamma lactone wave observed for this solution shifts toward more negative values as the wave height decreases, whereas the potential of the gamma lactone wave observed in the solution prepared from $d-\beta$-mannoheptonic acid 
shifts toward less negative values as the wave height increases. Thus the polarographic behavior of the lactone is consistent with the behavior of the acid. Shifts are also found in the waves for the lactones and acids of the configurationally related $d$-talonic and $d$ - $\alpha$-guloheptonic acids. Shifts in the potentials of the inflection points of the gamma lactone waves were observed in other instances, but the phenomenon does not appear to be characteristic of the gamma lactones of all aldonic acids. Frequently the determination of the inflection point is somewhat complicated by the presence of the $-2.3-\mathrm{v}$ wave, which merges into the gamma lactone wave and makes the measurement uncertain.

\section{2. $d-\alpha$-GULOHEPTONIC ACID AND ITS GAMMA LACTONE [26]}

A freshly prepared $0.01 M$ solution of $d$ - $\alpha$-guloheptonic acid in 0.1 $M$ tetraethylammonium chloride (fig. 12) showed only a wave at $-1.80 \mathrm{v}$ with a pointed maximum $53 \mathrm{~mm}$ high. When the solution was allowed to stand, the height of this wave decreased to zero, while wave $A$ appeared at $-1.18 \mathrm{v}$ after 47 hours and grew to a height of $4 \mathrm{~mm}$ at 458 hours. A wave developed slowly in the region from -2.6 to $-2.8 \mathrm{v}$. At 458 hours, this wave appeared to be composed of two waves with a total height of $33 \mathrm{~mm}$. One of these waves appeared to be the gamma lactone wave with an inflection point at $-2.6 \mathrm{v}$ and the other, the $-2.3 \mathrm{v}$ wave of unknown origin.

A freshly prepared $0.01 M$ solution of $d$ - $\alpha$-guloheptono- $\gamma$-lactone in $0.1 M$ tetraethylammonium chloride (fig. 12) showed a wave which began at $-2.1 \mathrm{v}$ and went off scale. From later curves it seems certain that this is due to two adjacent waves, the second of which, at approximately $-2.5 \mathrm{v}$, has a large maximum. This maximum becomes less pronounced in the course of time and is not noticeable at 143 hours. The first wave appeared to have its inflection point at $-2.3 \mathrm{v}$ and to be $25 \mathrm{~mm}$ high in the freshly prepared solution. At 94 hours the height of the $-2.3-\mathrm{v}$ wave had decreased to $15 \mathrm{~mm}$, and at 121 hours it had merged with the $-2.5-\mathrm{v}$ wave, which had become measurable at 94 hours. The sum of the heights of the two waves was $52 \mathrm{~mm}$ at 121 hours and decreased to $38 \mathrm{~mm}$ at 458 hours. Wave $A$ appeared at 143 hours and grew to $2 \mathrm{~mm}$ at 458 hours. The appearance of wave $A$ and the decrease in the height of the gamma lactone wave indicate hydrolysis of the lactone; but since the hydrogen wave failed to appear, any acid formed by hydrolysis of the lactone must have reacted further to give the substance responsible for wave $A$. The interpretation of the $-2.3-\mathrm{v}$ wave must await further investigation.

\section{3. $d$ - $\beta$-GULOHEPTONIC ACID [26]}

A freshly prepared $0.01 M$ solution of $d-\beta$-guloheptonic acid in 0.1 $M$ tetraethylammonium chloride showed only a hydrogen wave at $-1.78 \mathrm{v}$, with a pointed maximum. This wave was $57 \mathrm{~mm}$ high initially and decreased with time until after 457 hours it was not detectable. At 169 hours a wave began to develop in the region of $-2.6 \mathrm{v}$; at 191 hours it was at $-2.65 \mathrm{v}$ and was $9 \mathrm{~mm}$ high; at 457 hours it extended from -2.45 to $-2.80 \mathrm{v}$ and was $18 \mathrm{~mm}$ high. Since the $-2.6-v$ wave occurs in the region characteristic of the gamma lactones, it probably is caused by $d$ - $\beta$-guloheptono- $\gamma$-lactone, 


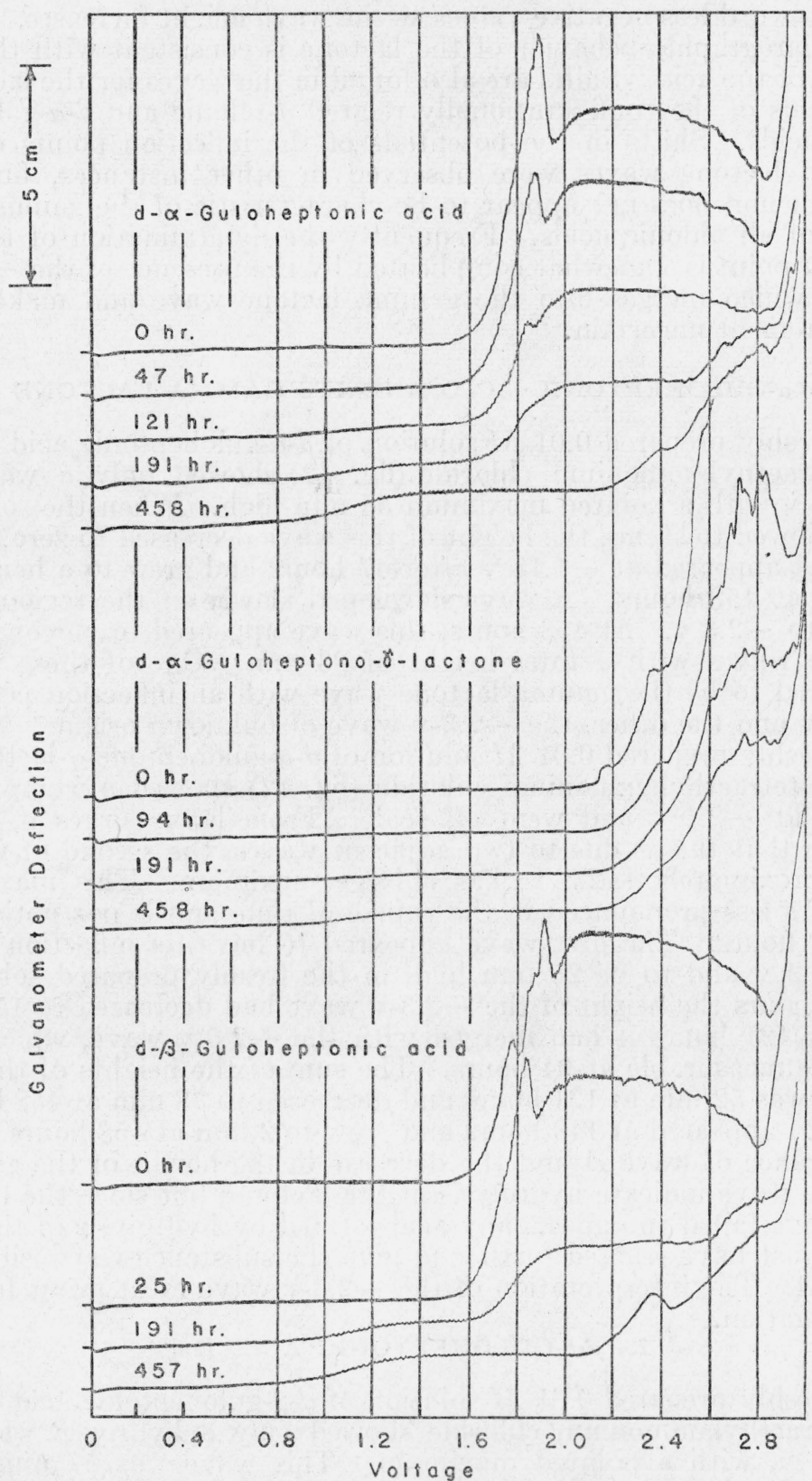

Figure 12.-Polarograms which show the effect of long standing, at room tempera-

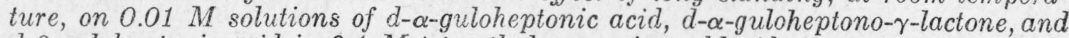
$d$ - $\beta$-guloheptonic acid in $0.1 \mathrm{M}$ tetraethylammonium chloride.

a sample of which was not available for comparison. In addition to the waves just described, wave $A$ at -1.13 v appeared after 47 hours and grew to $5 \mathrm{~mm}$ at 457 hours. Also, a $-2.2-\mathrm{v}$ wave $7 \mathrm{~mm}$ 
high appeared at 457 hours. The cause of the $-2.2-\mathrm{v}$ wave, which exhibited a rounded maximum, is not known, but it seems probable that it is related to the $-2.3-\nabla$ waves of unknown origin found for many of the polyhydroxy acids.

\section{LACTOBIONO- $\delta$-LACTONE [27]}

A freshly prepared $0.01 M$ solution of lactobiono- $\delta$-lactone in 0.1 $M$ tetraethylammonium chloride (fig. 2) showed a lactone wave at $-2.16 \mathrm{v}, 36 \mathrm{~mm}$ high, and a hydrogen wave at $-1.74 \mathrm{v}, 4 \mathrm{~mm}$ high. When the solution was allowed to stand, the lactone wave decreased rapidly as the hydrogen wave increased. At 25 hours the lactone wave was not detectable, and the hydrogen wave had grown to 53 $\mathrm{mm}$, with a pointed maximum. No further change was observed in 459 hours. The presence of a small hydrogen wave only 3 minutes after dissolution of the lactone and the disappearance of the lactone wave within 25 hours show that the lactone is hydrolyzed rapidly and that the equilibrium solution does not contain an appreciable quantity of lactobiono- $\delta$-lactone. A pointed maximum at $-2.7 \mathrm{v}$, $30 \mathrm{~mm}$ high with little, if any, diffusion current was observed in the freshly prepared solution. In 25 hours this maximum decreased to about $6 \mathrm{~mm}$, at which height it persisted up to 459 hours. Probably this maximum is caused by some impurity in the sample, possibly a condensation product of lactobionic acid.

\section{REFERENCES}

[1] O. H. Müller, Chem. Rev. 24, 95 (1939).

[2] R. Brdicka, Coll. Czech. Chem. Comm. 8, 419 (1936).

[3] J. J. Lingane, J. Am. Chem. Soc. 62, 1665 (1940).

[4] E. F. Mueller, Ind. Eng. Chem., Anal. Ed. 12, 171 (1940).

[5] H. S. Isbell, J. Research NBS 18, 505 (1937) RP990; 19, 639, (1937) RP1052; 20, 97 (1938) RP1069.

[6] G. M. Cantor and Q. P. Peniston, J. Am. Chem. Soc. 62, 2113 (1940).

[7] W. N. Haworth and V. St. Nicholson, J. Chem. Soc. 1926, p. 1899. P. A. Levene and H. S. Simms, J. Biol. Chem. 65, 31 (1925); 68, 737 (1926).

[8] I. M. Kolthoff and J. J. Lingane, Polarography, p. 111. (Interscience Publishers, Inc., New York, N. Y., 1941).

[9] Beilstein, 4th Ed. 3, 228; Supplement 3, 88.

[10] H. Ohle, Die Chemie der Monosaccharide und der Glykolyse, p. 29 (J. F Bergmann, München, 1931).

[11] T. Purdy and J. W. Walker, J. Chem. Soc. 6\%, 625 (1895).

[12] P. D. Watson, Ind. Eng. Chem., Ind. Ed. 32, 399 (1940).

[13] Beilstein, 4th Ed. 19, 154.

[14] G. Kimura, Coll. Czech. Chem. Comm. 4, 492 (1932).

[15] H. S. Isbell and H. L. Frush, BS J. Research 11, 649 (1933) RP613.

[16] E. Fischer and O. Piloty, Ber. deut. chem. Ges. 24, 4214 (1891).

[17] E. Fischer and O. Bromberg, Ber. deut. chem. Ges. 29, 581, 2068 (1896).

[18] O. F. Hedenburg and L. H. Cretcher, J. Am. Chem. Soc. 49, 478 (1927).

[19] E. Fischer and R. Stahel, Ber. deut. chem. Ges. 24, 528 (1891).

120] W. C. Austin and F. L. Humoller, J. Am. Chem. Soc. 55, 2167 (1933).

[21] E. Fischer, Liebigs Ann. Chem. 288, 141 (1895).

[22] H. Kiliani, Ber. deut. chem. Ges. 19, 767 (1886).

[23] K. Rehorst, Liebigs Ann. Chem. 503, 143 (1933).

[24] H. Fischer and J. Hirschberger, Ber. deut. chem. Ges. 22, 370 (1889).

[25] H. S. Isbell, J. Research NBS 20, 97 (1938) RP1069.

[26] H. S. Isbell, J. Research NBS 19, 639 (1937) RP1052.

[27] H. S. Isbell, BS J. Research 11, 713 (1933) RP618.

Washington, November 8, 1941. 


\section{NATIONAL BUREAU OF STANDARDS,}

WASHINGTON, D. C.

Send me the Mathematical Tables marked X below. I enclose remittance ${ }^{1}$ to cover the cost.

\begin{tabular}{|c|c|c|c|c|}
\hline \multirow[b]{2}{*}{ Mark X } & \multirow[b]{2}{*}{ Title of publication } & \multicolumn{2}{|c|}{ Price } & \multirow[b]{2}{*}{ Amount enclosed } \\
\hline & & $\begin{array}{l}\text { United States and } \\
\text { its possessions, } \\
\text { and countries ex- } \\
\text { tending franking } \\
\text { privilege }\end{array}$ & Other countries & \\
\hline (1) & $\begin{array}{l}\text { MT1. Table of the first ten powers of the integers from } 1 \text { to } \\
\text { MT2. Tables of the exponential function } e^{x} \\
\text { MT3. Tables of circular and hyperbolic sines and cosines for radian arguments } \\
\text { MT4. Tables of sines and cosines for radian arguments } \\
\text { MT5. Tables of sine, cosine, and exponential integrals, volume } \\
\text { MT6. Tables of sine, cosine, and exponential integrals, volume II } \\
\text { MT7. Table of natural logarithms, volume I } \\
\text { MT8. Tables of probability functions, volume I } \\
\text { MT9. Table of natural logarithms, volume II } \\
\text { MT10. Table of natural logarithms, volume III }\end{array}$ & $\begin{array}{r}\$ 0.50 \\
2.00 \\
2.00 \\
2.00 \\
2.00 \\
2.00 \\
2.00 \\
2.00 \\
2.00 \\
2.00\end{array}$ & $\begin{array}{r}\$ 0.65 \\
2.50 \\
2.50 \\
2.50 \\
2.50 \\
2.50 \\
2.50 \\
2.50 \\
2.50 \\
2.50\end{array}$ & 'מ- \\
\hline
\end{tabular}

1 Remittance should be in form of post-office money order, or check, and made payable to the order of the "National Bureau of Standards" in United States currency.

Send to

Number and Street

City and State 


\section{MATHEMATICAL TABLES}

Attention is invited to a series of publications which is being prepared by the Project for the Computation of Mathematical Tables conducted by the Federal Works Agency, Work Projects Administration for the City of New York under the sponsorship of the National Bureau of Standards.

To date, ten tables have been made available through the National Bureau of Standards. These are listed below:

MT1. T Able of thr First Ten Powers of the Intrgers From 1 to 1000:

(1938) VIII+ 80 pages; heavy paper cover. 50 cents.

MT2. Tables of the Exponential Function $e^{x}$ :

The ranges and intervals of the argument and the number of decimal places in the entries are given below:

$\begin{array}{ccc}\text { Range of } x & \text { Interval of } x & \text { Decimals given } \\ -2.5000 \text { to } 1.0000 & 0.0001 & 18 \\ 1.0000 \text { to } 2.5000 & .0001 & 15 \\ 2.500 \text { to } 5.000 & .001 & 15 \\ 5.00 \text { to } 10.00 & .01 & 12\end{array}$

(1939) XV +535 pages; bound in buckram, $\$ 2.00$.

MT3. Tables of Circular and Hyperbolic Sines and Cosings por Radian Arguments:

Contains 9 decimal place values of $\sin x, \cos x, \sinh x$ and $\cosh x$ for $x$ (in radians) ranging from 0 to 2 at intervals of 0.0001 .

(1939) XVII+ 405 pages; bound in buckram, $\$ 2.00$.

MT4. Tabies or Sines and Cosines for Radian Arguments:

Contains 8 decimal place values of sines and cosines for radian arguments ranging from 0 to 25 at intervals of 0.001 .

(1940) XXIX+275 pages; bound in buckram, $\$ 2.00$.

MT5. Tables of Sing, Cosing, and Exfonential Integrals, Volume I:

Values of these functions to 9 places of decimals from 0 to 2 at intervals of 0.0001 .

(1940) XXVI+444 pages; bound in buckram, $\$ 2.00$.

MT6. Tables of Sine, Costne, and Exponential Intrgrals, Volume II:

Values of these functions to 9,10 , or 11 significant figures from 0 to 10 at intervals of 0.001 , with auxiliary tables.

(1940) XXXVII + 225 pages; bound in buckram, $\$ 2.00$.

MT7. Table of Natural Logarithms, Volumb I:

Logarithms of the integers from 1 to 50,000 to 16 places of decimals.

(1941) XVIII + 501 pages; bound in buckram, $\$ 2.00$.

MT8. Tables of Probability Functions, Volume I:

Values of these functions to 15 places of decimals from 0 to 1 at intervals of 0.0001 and 1 to 5.6 at intervals of 0.001 .

(1941) XXVIII + 302 pages; bound in buckram, $\$ 2.00$.

MT9. Table or Natural Logarithms, Volume II:

Logarithms of the integers from 50,000 to 100,000 to 16 places of decimals.

(1941) XVIII + 501 pages; bound in buckram; $\$ 2.00$.

[Continued on p. 4 of cover] 
MT10. Table of Natural Logarithms, Volume III:

(Logarithms of the decimal numbers from 0.0001 to 5.0000 , to 16 places of decimals.) (1941) XVIII + 501 pages; bound in buckram, $\$ 2.00$.

Payment is required in advance. Make remittance payable to the "National Bureau of Standards", and send with order, using the blank form facing page 3 of the cover.

The prices are for delivery in the United States and its possessions and in countries extending the franking privilege. To other countries the price of MT1 is 65 cents and that of MT2, MT3, MT4, MT5, MT6, MT7, MT8, MT9, and MT10 is $\$ 2.50$ each; remittance to be made payable in United States currency.

Copies of these publications have been sent to various Government depositories throughout the country, such as public libraries in large cities, and colleges and universities, where they may be consulted.

A mailing list is maintained for those who desire to receive announcements regarding new tables as they become available. A list of the tables it is planned to publish will be sent on request. 